\title{
Exogenous Control of the Expression of Group I CD1 Molecules Competent for Presentation of Microbial Nonpeptide Antigens to Human T Lymphocytes
}

\author{
Angelo Aquino, ${ }^{1}$ Grazia Graziani, ${ }^{1}$ Ornella Franzese, ${ }^{1}$ Salvatore P. Prete, ${ }^{1}$ Enzo Bonmassar, ${ }^{1}$ \\ Laura Bonmassar, ${ }^{2}$ and Stefania D'Atri' \\ ${ }^{1}$ Department of Neuroscience, University of Rome "Tor Vergata", Via Montpellier 1, 00133 Rome, Italy \\ ${ }^{2}$ Laboratory of Molecular Oncology, Istituto Dermopatico dell'Immacolata-IRCCS, Via dei Monti di Creta 104, 00167 Rome, Italy \\ Correspondence should be addressed to Stefania D’Atri, s.datri@idi.it
}

Received 15 October 2010; Revised 12 January 2011; Accepted 19 January 2011

Academic Editor: Carl Feng

Copyright () 2011 Angelo Aquino et al. This is an open access article distributed under the Creative Commons Attribution License, which permits unrestricted use, distribution, and reproduction in any medium, provided the original work is properly cited.

Group I CD1 (CD1a, CD1b, and CD1c) glycoproteins expressed on immature and mature dendritic cells present nonpeptide antigens (i.e., lipid or glycolipid molecules mainly of microbial origin) to T cells. Cytotoxic CD1-restricted T lymphocytes recognizing mycobacterial lipid antigens were found in tuberculosis patients. However, thanks to a complex interplay between mycobacteria and CD1 system, $M$. tuberculosis possesses a successful tactic based, at least in part, on CD1 downregulation to evade CD1-dependent immunity. On the ground of these findings, it is reasonable to hypothesize that modulation of CD1 protein expression by chemical, biological, or infectious agents could influence host's immune reactivity against $M$. tuberculosis-associated lipids, possibly affecting antitubercular resistance. This scenario prompted us to perform a detailed analysis of the literature concerning the effect of external agents on Group I CD1 expression in order to obtain valuable information on the possible strategies to be adopted for driving properly CD1-dependent immune functions in human pathology and in particular, in human tuberculosis.

\section{Introduction}

Cell-mediated immunity involved in host resistance against mycobacteria and other infectious agents appears to rely to a large extent on classical HLA-restricted responses against microbial peptides [1] mediated mainly by interferon (IFN) $\gamma$-producing T-cells [2]. However, in recent years growing attention has been given to T-cell-mediated responses directed against lipid or glycolipid antigens presented by four relatively nonpolymorphic CD1molecules ([3-5], reviewed in [6]).

Two groups of CD1 isoforms expressed on the cell membrane of various antigen-presenting cells (APCs) have been identified in the course of the last 20 years. In particular, Group I (i.e., CD1a, CD1b, CD1c) and the isoform CD1e, that is confined to the intracellular compartment and is classified as Group III by some authors, are detectable in man but not in mice. On the contrary, Group II (i.e., CD1d, a biological entity outside the scope of the present review) is expressed in mice and men as well, and is involved in Invariant Natural Killer T-cell responses (specifically reviewed in [7]). The molecular structure of CD1 is similar to that of MHC class I. Both CD1 and MHC class I are comprised of heavy chains of similar length, which are organized into three extracellular domains $(\alpha 1, \alpha 2$, and $\alpha 3)$ and bind $\beta 2$ microglobulin.

Group I CD1 molecules are expressed most prominently on APCs of the myeloid lineage, including dendritic cells (DCs) derived from circulating monocytes (MOs). Peripheral blood $\mathrm{CD}^{-} / \mathrm{CD} 14^{+}$MOs can be activated by granulocyte-macrophage colony stimulating factor (GMCSF) alone or more efficiently in combination with interleukin-4 (IL-4) (i.e., GM-CSF + IL-4, hereafter referred to as G4) to express Group I CD1 glycoproteins $[9,10]$. These molecules are the products of the CD1A, $-B$, and $-C$ genes and are known to be involved in the presentation of nonpeptide microbial antigens to T-cells [6, 10-12]. In particular, Beckman et al. in 1994 [13] discovered that the CD1b-presented antigens obtained from Mycobacterium 


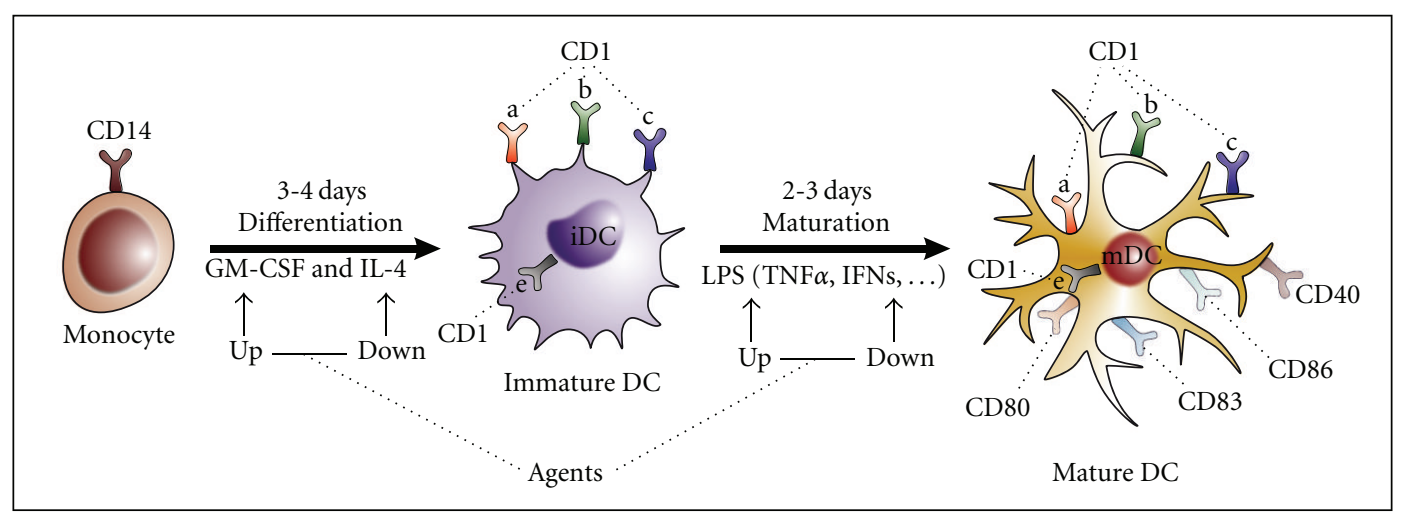

Figure 1: Dendritic Cell (DC) generation and maturation. Schematic drawing depicting the differentiation of monocytes to immature DC (iDC), generation of mature DC (mDC) and cytokines involved in these processes. Dotted lines point to the modulating effects of external agents.

tuberculosis were mycolic acids, that is, lipids associated with microbial cell wall. Later, it was demonstrated that CD1 molecules are competent for presentation of a great variety of microbial antigenic lipid structures to T-cells, so that CD1 could be tentatively considered a wide spectrum system of anti-infectious immune surveillance [6].

Particular attention of the present review is dedicated to the studies concerning the CD1 system predominantly engaged in antitubercular responses, and therefore involved in mycobacterial lipid presentation to CD1-restricted T-cells. A fraction of responder T-cells comes from the $\mathrm{CD} 4^{-} / \mathrm{CD}^{-}$ phenotypic subset of $\mathrm{CD}^{+} \mathrm{T}$-cell receptor (TCR) $\alpha / \beta$ T-cells. These cells, sometimes referred to as double-negative TCR $\alpha / \beta \mathrm{T}$ lymphocytes [14], proliferate and generate cytotoxic clones following interaction with mycobacterial glycolipids, presented by $\mathrm{CD} \mathrm{b}^{+}$DCs-derived from G4-preactivated MOs. However, CD1-restricted $\mathrm{CD}^{+}{ }^{+}$or $\mathrm{CD} 4^{+} \mathrm{TCR} \alpha / \beta \mathrm{T}$ cell clones $[15,16]$ and TCR $\gamma / \delta$ T-cells $[3,17]$ have also been demonstrated. Thus, responder cells that potentially play a role in CD1-restricted responses to nonpeptide antigens, have been found to belong to all of the major phenotypic subsets of T-cells. Noteworthy is the general observation that CD1-restricted recognition of bacteria-associated lipids results in killing of the infected cells as well as of the microorganism, thus providing presumably a way to prevent infection spreading in the host $[15,18]$.

The induction of effector T-cells against microbial antigens is accompanied by the presence of autoreactive CD1restricted T-cells directed against self-lipid antigens [19]. These lymphocytes appear to cooperate in early suppression of invading microorganisms, in the induction of CD1restricted memory T-cells and in the maturation of DCs able to produce substantial amounts of IL-12. In turn, IL12 stimulates T-cells to produce IFN $\gamma$ (reviewed in [20]) and plays an important role in antitubercular immunity [21]. Autoreactive CD1-restricted T-cells have also been accused to take part in the immune mechanisms underlying multiple sclerosis (MS) and Guillan-Barre syndrome $[22,23]$. However, detection of autoreactive cytotoxic T lymphocytes in patients affected by autoimmune disease, does not necessarily mean that these cells play a role in the pathological events affecting target organs.

Up to now, it has not been definitely established whether tuberculosis prevention could be achieved through vaccinial procedures based on M. tuberculosis-associated lipids as sensitizing agents. Improvement in the course of the disease has been noted in guinea pigs sensitized with lipid extracts of M. tuberculosis [24, 25]. Moreover, a recent study published by Felio et al. [26] showed that human Group I CD1 transgenic mice are competent for mounting a CD1restricted adaptive immune responses to mycobacteria, thus allowing further preclinical investigations on lipid-based antitubercular vaccines in mouse models.

In view of a potential role of Group I CD1 glycoproteindependent presentation of mycobacterial lipids to T-cells, it is reasonable to hypothesize that pharmacological or biological agents able to modulate CD1 expression could modify host's responses against infectious diseases, including infections caused by M. tuberculosis. Therefore, the aim of the present short survey is to illustrate the data presently available in the literature, relative to the influence that can be exerted by external agents on Group I CD1 molecule expression. In particular, the reported studies will consider human MOs driven in vitro or in vivo to differentiate into immature and thereafter mature DCs (Figures 1 and 2) competent for peptide or nonpeptide molecule presentation to T-cells.

\section{In Vitro and In Vivo Assays of CD1 Induction}

A classical experimental design to explore the functional pathways involved in the differentiation and maturation of human myeloid DCs in vitro system, starting from purified $\mathrm{CD} 14^{+}$MOs obtained from peripheral blood mononuclear cells (PBMNC), can be described as follows (Figure 2):

Step 1. In vitro cultivation of MOs with G4 for 3-6 days (or, in some cases, for up to 7 days). This treatment is able to induce "immature DCs" (iDCs) showing high expression of CD1a, CD1b, and CD1c glycoproteins on cell membrane, competent for lipid antigen presentation to CD1-restricted T-cells. 
Experiment design (ED) codes

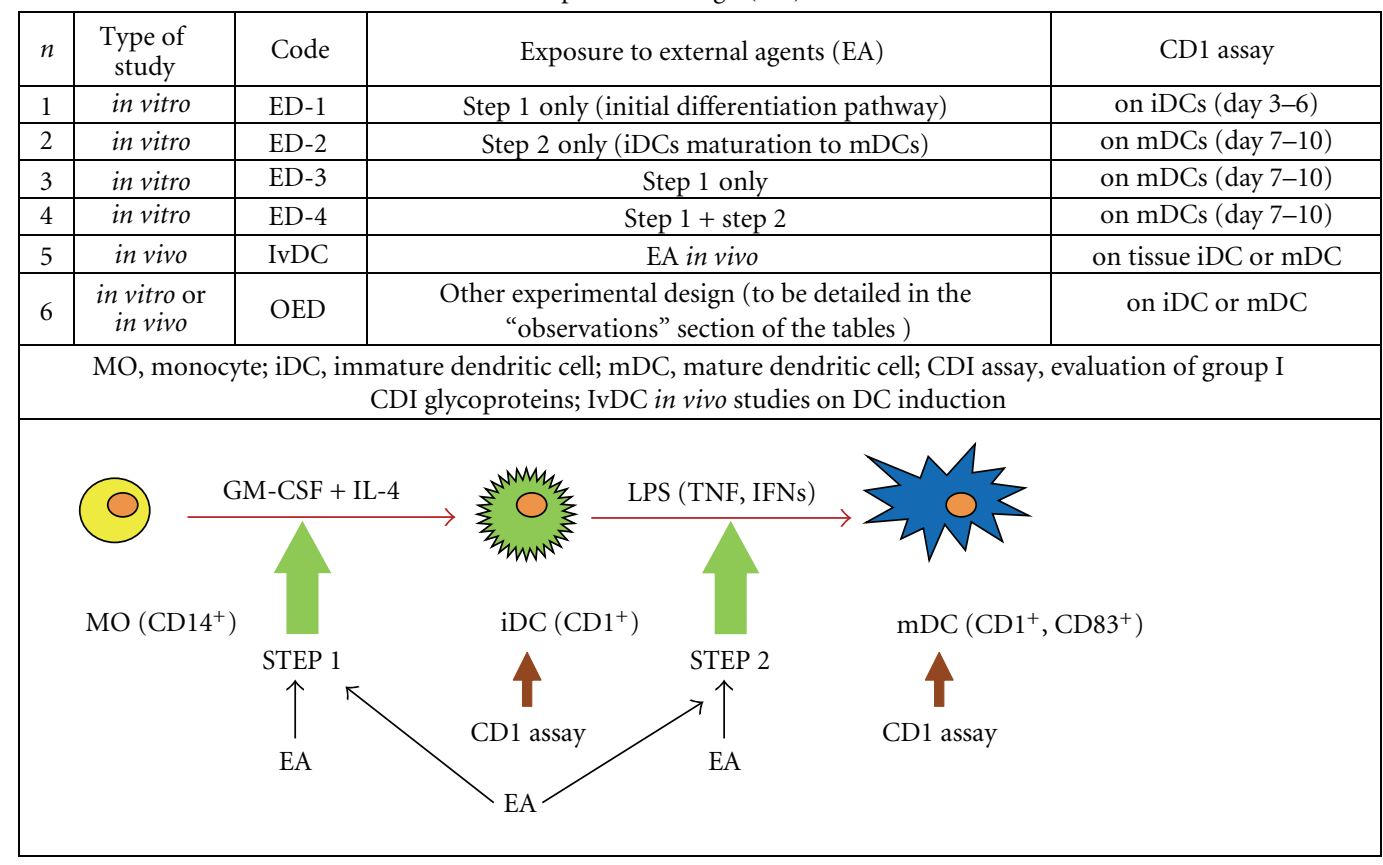

FIGURE 2: Effect of external agents on group I CD1 glycoprotein expression.

Step 2. In vitro culture of iDCs with lipopolysaccharide (LPS) and/or various cytokines (e.g., $\mathrm{TNF} \alpha, \operatorname{IFN} \alpha, \mathrm{TGF} \beta$, etc.) for additional 2-3 days, leading to mature CD83 ${ }^{+}$DCs (mDCs), fully competent to behave as classical APCs.

In a large number of studies published in more than 15 years, iDCs have been also generated from cord blood CD $34^{+}$ cells cultured in vitro with a cocktail of cytokines containing GM-CSF. In addition, several investigations have been conducted in vivo by evaluating the number of DCs in various organs, in different clinical and treatment conditions using immunohistochemical detection of mainly $\mathrm{CD} \mathrm{a}^{+}$cells.

All these methods, able to explore the functional pathways leading to mDCs, allowed to test the effect of a number of exogenous agents on the expression of Group I CD1 molecules induced in host's cell population involved in resistance against pathogens, including mycobacteria.

In order to offer a concise picture on the external control of CD1 expression, the present review provides information on the complex relationship between mycobacteria and CD1 levels, and four tables summarize schematically what we presently know on the regulation of CD1 expression by pharmacological and biological agents. Moreover, with the intent to provide a simplified information on the experimental strategy utilized for studying the influence exerted by exogenous agents on CD1 expression during myeloid DCs induction and maturation, we decided to adopt the codes that are illustrated in Figure 2.

\section{CD1 Expression}

It is generally agreed that transcriptional control of gene expression and posttranscriptional regulation of mRNA function are usually under the control of proteins targeting specific DNA sequences (i.e., transcription factors) and microRNAs, respectively. In particular, expression of Group I CD1 genes is under the control of transcription factors, that have been described in detail for CDla glycoprotein by Colmone et al. [27]. A minimal 1000-bp region upstream of the translation start site has been identified as necessary for proximal promoter activity required for $C D 1 A$ transcription. This region contains multiple sites that were considered to be coordinatively involved in CD1A gene expression on the basis of a series of experiments performed by means of deletion and site-specific mutant analysis. In particular, a critical role appeared to be played by a potential cAMP response element (CRE), $965 \mathrm{bp}$ upstream of the CD1A translation start site. It was found that the CRE-binding protein 1 (CREB-1) and the activating transcription factors2 (ATF-2) that are enlisted among the ATF/CREB family members, are able to bind this site in vitro and in vivo in various cell types, including human MOs [27]. Moreover, the results of these studies speak in favour of ATF-2-induced inhibition counterbalanced by a stimulatory activity on gene transcription by CREB-1, possibly through a competition of CREB-1 and ATF-2 for CRE binding. The hypothesis of opposite control performed by two transcription factors acting on the same gene promoter appears to be supported by the studies published by Niwano et al. [28] who proposed a similar mechanism for endothelial nitric oxide synthase.

In the present survey of the literature, we noticed the emerging role played by miRNAs on hematopoiesis (reviewed in [29]). Therefore, we have considered the possibility that miRNAs could affect CD1 expression. An in silico analysis was performed using the miRanda (http://www.microrna.org/) and TargetScan (http://www.targetscan.org/) algorithms for miRNA target prediction. Under miRanda 
analysis, miRNA list indicates conserved miRNAs with good mirSVR scores [8]. As illustrated in Table 1, this analysis revealed that mRNAs transcribed from all three Group I $C D 1$ genes can be targeted and potentially regulated at the $3^{\prime}$ UTR region by a number of different miRNAs. In particular, 10 miRNAs have been found to share a potential capability of controlling the transcriptional activity of two CD1 genes. Six miRNAs (i.e., 33a, 33b, 421, 495, 590-3p, and 590-5p) could target both CD1a and CD1c, whereas miRNA-224 could be active on CD1a and CD1b, and 3 miRNAs (i.e., 129-5p, 185 and 203) appear to be theoretically competent to target CD1b and CD1c. However, up to now no study able to validate the in silico prediction patterns is available from the literature. Nevertheless, a number of miR genes have been found to be involved in the regulation of immune responses [30,31] and acute inflammation [32]. Moreover, quite recently Kuipers et al. [33] described that microRNAs control maturation, function, and maintenance of DCs in the epidermis (i.e., Langerhans cells, LC) in vivo. In addition, exchange of genetic material between prokaryotic and eukaryotic multicellular organisms has been described [34]. Therefore, since pathogenic microorganisms, including mycobacteria contain a large amount of small noncoding RNA [35, 36], it is reasonable to hypothesize that invading microbes could control gene expression of host eukaryotic cell through their miRNA-like molecules to acquire a survival advantage.

\section{Mycobacteria and CD1 Expression}

Anti-tubercular immunity relies on humoral and cellmediated immune responses against $M$. tuberculosisassociated epitopes of various origin, and possibly includes CD1-presented lipid antigens recognized by dedicated T-cell subpopulations [37]. More than eighty years ago, attenuated strains of $M$. bovis (i.e., Bacillus Calmette-Guerin, BCG) were developed and utilized as antitubercular vaccine, since they share a variety of antigenic molecules with virulent pathogenic bacilli [38]. Although BCG vaccine reduces the risk of severe forms of tuberculosis in early childhood, unfortunately it is not very effective in preventing the pulmonary infection in adolescents and adults, the populations with the highest rates of tuberculosis disease. Moreover, $M$. tuberculosis is changing and evolving, making the development of new vaccines [39] more crucial to control the disease that is continuously expanding, favored, at least in part, by AIDS pandemia.

In the last years, a considerable amount of experimental studies has been dedicated to investigate the complex relationship between the infection with virulent $M$. tuberculosis or BCG and functional activity of the CD1 system. A number of studies confirm that lipid antigens recognized and presented by Group I CD1 glycoproteins include fatty acids isolated from M. tuberculosis cell wall [40]. Among others, they comprise the fatty-acid-derived mycolic acid, the lipopeptide didehydroxymycobactin [41], the isoprenoidlike structure mannosyl phosphomycoketide [42], and the acylated sulfoglycolipid Ac2SGL [43].
TABLE 1: miRNAs with putative binding sites in the $3^{\prime} \mathrm{UTR}$ of $C D 1 A$, $C D 1 B$, and $C D 1 C$ genes.

\begin{tabular}{|c|c|c|}
\hline \multirow[t]{2}{*}{ Gene } & \multicolumn{2}{|c|}{ Algorithm } \\
\hline & miRanda ${ }^{a}$ & Target Scan ${ }^{\mathrm{b}}$ \\
\hline$C D 1 A$ & $\begin{array}{l}19 \mathrm{a}, 21,28-5 \mathrm{p}, 31 \\
33 \mathrm{a}, 33 \mathrm{~b}, 146 \mathrm{a} \\
146 \mathrm{~b}-5 \mathrm{p}, 214,217 \\
361-5 \mathrm{p}, 383,421,448 \\
495,590-3 \mathrm{p}, 590-5 \mathrm{p}, \\
708,873\end{array}$ & $\begin{array}{l}\text { 21, 28-5p, 31, 33a, } \\
\text { 33b, 125a-3p, 138, } \\
\text { 146a, 146b-5p, 197, } \\
\text { 205, 224, 421, 448, } \\
\text { 495, 590-5p, } 708\end{array}$ \\
\hline$C D 1 B$ & $\begin{array}{l}129-5 p, 137,185,203 \\
224,543\end{array}$ & $129-5 p, 137,203,543$ \\
\hline CD1C & $\begin{array}{l}\text { 26a, 26b, 33a, 124, } \\
\text { 125a-5p, 125b, } \\
\text { 129-5p, 181a, 181b, } \\
\text { 181c, 181d, 190, 190b, } \\
\text { 203, 216a, 216b, 218, } \\
\text { 219-5p, 300, 326, } \\
\text { 330-5p, 340, 367, } \\
\text { 376a, 376b, 381, 410, } \\
421,433,455-5 p, 494, \\
495,505,506,539, \\
543,590-3 p, 1297\end{array}$ & $\begin{array}{l}\text { 22, 26a, 26b, 33a, } \\
\text { 33b, 124, 125a-5p, } \\
\text { 125b, 129-5p, 132, } \\
\text { 185, 190b, 203, 212, } \\
\text { 216a, 216b, 218, } \\
\text { 219-5p, 221, 222, 300, } \\
326,330-5 p, 376 a, \\
376 b, 410,495,425, \\
433,455-5 p, 489,494, \\
505,506,539,542-3 p, \\
543,590-5 p, 599, \\
1297\end{array}$ \\
\hline
\end{tabular}

${ }^{a}$ Conserved miRNAs with good mirSVR scores [8].

${ }^{b}$ miRNAs broadly conserved among vertebrates (bold) or conserved only among mammals.

In this context, CD1b appears to play a particularly important role, since CD1b-restricted T lymphocytes recognize a large variety of mycobacterial lipids [44], including M. tuberculosis Ac2SGL antigens [45]. Moreover, CD1b groove is much larger than that associated with the other CD1 isoforms, so that it can adjust long chain foreign lipids, including long mycobacterial mycolates that are not presented by the other CD1 molecules [46]. On the basis of all these findings and taking into account additional information from the literature (reviewed in $[6,46]$ ), it is reasonable to consider Group I CD1 as a relevant part of the complex antigen-presenting systems involved in the T-celldependent immune response machinery against mycobacteria. Actually, in human leprosy lesions CD1 expression correlates with host immunity as manifested by active cellular immunity to M. leprae [47]. A number of clinical and experimental data indicate that long-lived immunity to M. tuberculosis relies largely on antigen-specific $\mathrm{CD}^{+}$and $\mathrm{CD}^{+} \mathrm{T}$-cells that could play consistent roles in vaccination strategies [48]. Therefore it is reasonable to hypothesize that CD1-restricted effector $\mathrm{T}$ lymphocytes, that show a limited repertoire but are able to recognize large amounts of lipid antigens based on antigenic cross-reactivity [49], would contribute to antitubercular immunity. Ulrichs et al. [50] collected PBMNC from patients with pulmonary tuberculosis, from asymptomatic individuals with known contact with $M$. tuberculosis documented by conversion of their tuberculin skin tests, and from healthy tuberculin skin test negative subjects. In vitro, in presence of autologous $\mathrm{CD}^{+}{ }^{+}$iDCs, the extent of CD1-restricted T-cell responses to a lipid extract of $M$. tuberculosis was tested by means 
of proliferation and IFN $\gamma$ production by effector T-cells. The results showed that T-cells from asymptomatic $M$. tuberculosis-infected donors were significantly more responsive than those obtained from uninfected healthy donors. Moreover, essentially no CD1-restricted T-cell response was detectable in lymphocytes collected from patients with active tuberculosis prior to chemotherapy. However, significant antilipid immune reactivity became detectable in blood samples drawn two weeks after the start of treatment, as a possible consequence of chemotherapy-induced relief of the inhibitory effect exerted by mycobacteria on cell-mediated immunity [51].

In order to better define the possible role that can be played by CD1-dependent antimycobacterial immunity, it is important to identify the target of CD1-restricted effector T-cells and the modality of target suppression. Of note are the findings illustrated by Vincent et al. [52] who used CD1restricted human $\alpha / \beta$ T-cells generated by autologous DCs in presence of microbial detergent extracts from $M$. tuberculosis, E. coli, or Y. enterocolitica. Effector T-cells were found to be active in terms of proliferation and IFN $\gamma$ release when tested against target cells presenting microbial lipid antigens via CD1a, CD1b, or CD1c molecules. However, similar activity, although to a lower extent, was detected in absence of foreign lipids, thus indicating that sensitized lymphocytes were also endowed with effector function against self-lipids. The authors propose that CD1-restricted T lymphocytes fit in two T-cell populations, that is, naive $\mathrm{T}$ lymphocytes able to mount an adaptive response to microbial lipids as well as memory/effector T-cells. The latter population, characterized by reactivity against self and foreign lipids, would be particularly dedicated to rapid initial immune responses against invading pathogens and yet able to undergo clonal expansion responsible for long-standing cellular memory to foreign lipid antigens. Actually, Nguyen et al. [53] have recently reported that upon experimental vaccination of cattle, CD1b-restricted memory T-cell response can be elicited by the mycobacterial glycolipid glucose monomycolate.

The effector function of $\mathrm{T}$ lymphocytes against microbial targets, including $M$. tuberculosis follows a rather complex pattern (reviewed in [20]). When primed T-cells interact with $\mathrm{CD}^{+}$mycobacteria-infected target cells, they kill directly mycobacteria through granulysin/perforin-based mechanism release [54], or they induce Fas-dependent apoptotic death of target cells without killing the intracellular infectious agent. In this case mycobacteria are released and infect adjacent macrophages and DCs where invading bacilli are possibly killed, depending on microbial burden. In addition to direct cytotoxic effects, CD1-restricted Tlymphocytes release Th1 cytokines (i.e., IFN $\gamma$ and TNF $\alpha$ ) that activate the microbicidal functions of macrophages and DCs [20].

Recently, the role of IFN $\gamma$ released by CD1-restricted effector T-cells has been subjected to detailed analysis by Lee and Kornfeld [55]. These authors reported that IFN $\gamma$ released by T-cells inhibits bacterial replication in infected macrophages carrying low intracellular burden of mycobacteria, thus contributing to host defenses against tuberculosis. However, when macrophages are engulfed with high bacteria load, IFN $\gamma$ facilitates host cell death, thus promoting necrosis and spreading of the infection, with potentially adverse effects on the course of the disease.

A large body of experimental data is presently available from the literature showing that mycobacteria have developed highly sophisticated strategies to escape host's resistance based either on innate or adaptive immunity (reviewed in [56]). Tuberculosis is predominantly a lung disease characterized by long chronic course due to persistent and sometimes dormant infection. It is well documented that upon contact with inhaled $M$. tuberculosis, both alveolar macrophages, that do not express $\mathrm{CD} 1$ molecules, and $\mathrm{CD}^{+}$ DCs phagocytose mycobacteria. But most of the microorganisms are taken up by macrophages that are by far more efficient than resident lung DCs in the ability to phagocytose and possibly kill bacteria [57]. However, the fate of $M$. tuberculosis within the infected alveolar macrophage depends on the state of activation of the phagocyte. Actually, the bacillus is able to survive preferentially within a macrophage subpopulation displaying an anti-inflammatory phenotype with a reduced oxidative burst. Moreover, phagocytosed mycobacteria end up in a phagosome, the maturation of which is arrested at an early stage [58], at least in part by mycobacteria-released glycolipids, such as lipoarabinomannan and phosphatidylinositol mannoside [59]. M. tuberculosis inhibits phagosomal acidification, prevents phagosomelysosome fusion and survives within macrophages by avoiding lysosomal delivery thanks, at least in part, to coronin 1 that is actively recruited to mycobacterial phagosomes [60]. Since alveolar macrophages do not express CD1 molecules, and mycobacterial peptide antigens confined to phagosomes are excluded from the classical MHC-I presentation pathway, they cannot be targeted by MHCI- or CD1-restricted cytotoxic lymphocytes. Therefore, in the lung environment, host's defenses against mycobacteria are mainly activated through apoptosis induction of infected alveolar macrophages followed by cross-priming of resident DCs endowed with the appropriate machinery for peptide and lipid/glycolipid antigen presentation to T-cells [61]. However, mycobacterial infection inhibits specifically macrophage apoptosis [62], thus preventing DC cross-priming and consequently providing an additional mechanism of impairment of host's T-cell defenses based on bacterial antigen recognition.

Infection with $M$. tuberculosis can also adversely affect DC function by interfering with their expression pattern of antigen-presenting molecules. Therefore, among the different escape mechanisms operated by mycobacteria, of particular relevance for the present survey are the complex autocrine and paracrine devices that the microorganism uses to control the induction of Group I CD1 molecule expression in infected and adjacent noninfected MOs. In 1998 Stenger et al. [63] exposed in vitro MOs from healthy donors to G4 for 3 days, obtaining iDCs expressing high levels of Group I CD1 glycoproteins. Thereafter, iDCs were heavily infected with $M$. tuberculosis that was able to suppress entirely CD1 expression within $24 \mathrm{~h}$ independently from any cytokine intervention. On the other hand, Prete et al. [64] reported later that in vitro coculture of BCG with untreated MOs was able to induce 
GM-CSF release by infected cells leading to limited CD1b expression. Modest upregulation of Group I CD1 antigen expression was also described by Roura-Mir et al. [65] in untreated MOs after in vitro infection with $M$. tuberculosis at 2 or 10 bacteria per cell. These authors report that their findings could be explained, at least in part, through Toll-like receptor-2 (TLR-2) signaling induced by mycobacterial cell wall lipids. A possible, although limited induction of CD1 expression by mycobacteria has also been described in vivo. Videira et al. [66] found that prophylactic administration of intravesical BCG to prevent tumor recurrence in bladder cancer patients, was followed by upregulation of $C D 1 A$, $C D 1 B, C D 1 C$, and $C D 1 E$ gene transcripts in cells obtained from urothelium biopsies. This effect was significantly higher in patients with a more favorable response with respect to that observed in patients with early tumour recurrence [66]. Marked accumulation of $\mathrm{CD} \mathrm{a}^{+} \mathrm{LC}$ after mycobacterial stimuli was also described in leprosy skin lesions [67]. On the other hand, in vitro maturation of $\mathrm{MOs}$ to $\mathrm{CD} 1 \mathrm{a}^{+}$ DCs under the influence of G4 and LPS was found to be sensibly impaired when MOs were collected from patients with pulmonary tuberculosis [68]. The intriguing Januslike behavior of mycobacteria relative to CD1 expression has been investigated in 2001 by Prete et al. [69] and Giuliani et al. [70], who found that BCG induced in vitro a limited expression of CD1 in untreated MOs from healthy donors, but inhibited markedly G4-induced CD1 upregulation in the same cells. Thereafter, further investigations confirmed that in vitro infection with mycobacteria downregulates CD1 expression [71, 72]. In particular, upon exposure to G4, MOs infected with M. smegmatis failed to express CD1a and evolved directly into CD83 ${ }^{+}$mDCs [73]. In 2007, Prete et al. [74] provided direct experimental evidence that in vitro exposure of healthy MOs to BCG induced release of both GM-CSF and IL-10, and that the interplay between the two cytokines was presumably involved, at least in part, in the Janus-like behavior of BCG. Actually, early GM-CSF release was responsible for the limited autocrine and paracrine CD1 induction. On the other hand, slightly delayed appearance in culture medium of IL-10 produced by BCG-infected MOs contributed to the severe limitation of further increase of $\mathrm{CD} 1$ proteins, even in the presence of exceedingly high concentrations of added GM-CSF. More recently, Gagliardi et al. [75] reported that mycobacteria trigger phosphorylation of p38 mitogen-activated protein kinase (p38 MAPK) in human MOs, leading to CD1 expression impairment. In fact, pretreatment with a specific p38 MAPK inhibitor allows infected MOs to differentiate into $\mathrm{CD1}^{+} \mathrm{DCs}$, which are fully capable of presenting lipid antigens to specific T-cells. Further studies have been conducted on the possible role of cytokines in restraining the GM-CSF-induced upregulation of Group I CD1 glycoproteins in mycobacteria infected MOs. Quite recently, Remoli et al. [76] confirmed the results of the studies described by Prete et al. [74] showing that IL-10 produced by MOs infected with $M$. tuberculosis is responsible for in vitro suppression of CD1. Moreover, consistently with the results obtained previously by the same group [75], they suggested that IL-10 release by infected MOs was induced by the activation of p38 MAPK signal transduction pathways. Several reports from the literature indicate that mycobacteria activate $I L-10$ gene and promote IL-10 release from MOs, phagocytes, and DCs through different intracellular pathways, including PI3K/AKT and p38 MAPK [77-81], phosphorylation and activation of dsRNA-activated serine/threonine protein kinase [82] and glycogen synthase kinase 3 [83]. Noteworthy is the role of proline-glutamic acid/proline-proline-glutamic acid family of proteins of $M$. tuberculosis that can stimulate macrophages to secrete IL-10 via activation of the TLR-2 leading to an early and sustained activation of p38 MAPK, which is critical for IL-10 induction [84]. The role of MAPK in the impairment of CD1 expression by mycobacteria has been also confirmed and emphasized very recently by Balboa et al. [85] who found that mycobacteria-induced loss of CD1b molecules partially involves TLR-2/p38MAPK activation.

Several other molecular mechanisms distinct from those relative to impairment of $\mathrm{CD} 1$ gene transcription could be involved in mycobacteria-induced decrease of CD1 expression or of antigen presentation efficiency. The complex cycle of CD1 biosynthesis, cell surface expression, and lipid loading $[12,44,86]$ highlights the several means by which mycobacteria can interfere with CD1 expression on cell membrane and antigen presentation to T-cells. After biosynthesis in the endoplasmic reticulum, CD1e remains in the cell, whereas all other CD1 molecules reach the cell surface through the Golgi and trans-Golgi network where they bind to self-lipids. Direct loading of lipids may occur at the plasma membrane, as described for glycosphingolipids that bind to $\mathrm{CD} 1 \mathrm{~b}$ on the cell surface at neutral $\mathrm{pH}$. Thereafter, glycosphingolipids are recognized without internalization or processing and stimulate specific T-cells [87]. Moreover, various cell-surface CD1a proteins are stabilized by exogenous glycosphingolipids and phospholipids present in serum [88].

As a rule, processing and presentation of microbial CD1-bound lipid antigens require that $\mathrm{CD} 1$ molecules, loaded with self-lipids, undergo a recycle process. CD1self lipid complexes are internalized, traffic through the endosomal compartments, where loading and/or exchange with exogenous lipid antigens occur, then the new CD1nonself lipid complexes re-emerge on plasma membrane. This process resembles peptide sampling by MHC class II proteins, although MHC class II molecules may reach the endocytic compartment directly from the trans-Golginetwork, without first travelling to the cell membrane.

Cell surface CD1 molecules are internalized according to two distinct mechanisms. Specifically, CD1a molecules, which lack a tyrosine-based internalization motif, are internalized to the early endosomes [89] through a clathrin/dynamin-independent manner and recycle back to the plasma membrane through a mechanism that relies on small GTPases, such as Rab22 and ADP-ribosylation factor 6. Both CD1b and CD1c molecules, instead, have a tyrosinebased motif in their cytoplasmic tail and are internalized through clathrin-coated pits via the adaptor protein 2 (AP2). Thereafter, CD1b is transported to the late endosomes and, after binding to AP-3, traffics to the lysosomes and then recycles to the plasma membrane. On the other hand, CD1c, 
after reaching the sorting endosomes, routes to the early endosomes, and, although to a lesser extent, to the late endosomes and lysosomes, and then recycles to the plasma membrane. It follows that $\mathrm{CD} 1 \mathrm{c}$ operates a comprehensive survey for lipid antigens throughout the endocytic system [90].

The entire CD1 recycling pattern reveals that a large variety of molecular targets could be affected by $M$. tuberculosis. In addition to that, it must be considered that intracellular lipid loading presumably requires the functional intervention of a number of helper and adaptor molecules, including saposins and apolipoproteins $[91,92]$ and CD1e itself $[93,94]$. Moreover, acidic $\mathrm{pH}$ promotes lipid binding to $\mathrm{CD} 1 \mathrm{~b}$ proteins, thus suggesting that $\mathrm{pH}$ fluxes during endosomal recycling regulate the conformation of the CD1 heavy chain to control the size and rate of antigen capture [95]. Within this context, it is worth of note the finding that mycobacteria impair phagosome acidification [58] thus reducing the extent of mycobacterial lipids bound to CD1b for T-cell presentation.

\section{HIV and CD1 Expression}

Interestingly enough, not only the mycobacterial infection, but also HIV or HTLV-1 infection or intracellular presence of HIV products are able to interfere with CD1 expression. For example, HIV-1-Nef was found to interfere with the intracellular trafficking of CD1a [96], although recombinant Nef added to iDCs increases CD1a expression [97]. Moreover, it must be pointed out that viable HIV-1 particles infect target $\mathrm{CD}^{+}$T-cells via CD1b ${ }^{+}$exosomes [98]. On the other hand, in 30 to $45 \%$ of HIV-infected white and African subjects, peripheral blood MOs exposed in vitro to G4 followed by LPS gave rise to CD1a ${ }^{-}$mDCs releasing IL-10 but not IL-12 [99]. In addition, DCs from HTLV-I-infected monocytes fail to present adequate amounts of CD1a glycoprotein [100].

Preliminary investigations of experimental design (ED)1 type (see ED codes illustrated in Figure 2) performed in our laboratory, revealed also a possible link between HIV infection and CD1 system, presumably relevant to the increased susceptibility of HIV-infected individuals to mycobacteria. A vector expressing tat DNA (PCV-TAT, [101]) under the control of the major adenoviral late protein, and a control empty vector (PCV-0) were kindly provided by Barbara Ensoli MD of the Italian National Institute of Health. Peripheral blood MOs of healthy donors were incubated with G4 alone or with G4 + a supernatant obtained from the human T-cell leukemia line Jurkat transfected with PCV-0 (sup-PCV-0) or with PCV-TAT (sup-PCV-TAT). The results of a representative experiment demonstrated that tatinduced factors released by transfected cells are able to downregulate $\mathrm{CD} 1 \mathrm{~b}$ expression. In fact, after 5-day exposure to G4 in vitro, iDCs generated in the absence of supernatants or in the presence of sup-PCV-0 showed $72 \%$ and $79 \%$ $\mathrm{CD} \mathrm{b}^{+}$cells, respectively. In contrast, when iDCs were generated in the presence of sup-PCV-TAT, the percentage of $\mathrm{CD} \mathrm{b}^{+}$cells dropped significantly to $54 \%$ (Franzese et al., in preparation). Moreover, if monoclonal antibodies against IL-10 were added to G4 + sup-PCV-TAT at the onset of iDC generation, the percentage of $\mathrm{CD}^{-} \mathrm{b}^{+}$cells raised to $81 \%$.
These results along with previous findings indicating that TAT induces IL-10 in MOs [102] and that IL-10 downregulates CD1 expression [74-76, 103-106], are consistent with the hypothesis that IL-10, generated in the presence of TAT, plays a critical role in compromising CD1b expression.

\section{Chemical, Biological, and Physical Agents Affecting CD1 Expression}

6.1. Drugs. A number of natural and synthetic compounds of pharmacological interest are able to modulate the expression level of Group I CD1 proteins on immature and/or mature DCs, either in vitro and in vivo, as reported in Table 2.

As expected, most of the immunosuppressant and antiinflammatory agents, including corticosteroids, nonsteroidal anti-inflammatory drugs (NSAID), and anti-asthma compounds, down-regulate cytokine-induced CD1 expression of MOs and impair their functional activity. However, local application of Pimecrolimus on skin in atopic dermatitis, is followed by increase in the number of $\mathrm{CD} 1 \mathrm{a}^{+}$cells. Moreover, in vitro exposure of $\mathrm{CD} 34^{+}$peripheral blood progenitor cells to Tacrolimus favors the expression of CD1a induced by 14-day treatment with cytokines. Notable exceptions to the inhibitory effects of anti-inflammatory drugs is also represented by Piceatannol (a stylbene compound similar to resveratrol) and terpenes that were found to increase CD1a expression after G4 treatment in vitro of MOs obtained from healthy donors. Of sensible relevance to the problem of MS therapy and identification of disease pathogenesis is the finding that Glatiramer acetate (GA), alone or in combination with IFN $\beta$, is able to down-regulate CD1 expression in vitro or in vivo. Similar inhibitory effects have been described in vitro with vitamin D3 that shows beneficial effects in MS management. These observations appear to provide further support to the hypothesis that significant participation of CD1-restricted T-cell responses against self lipid antigens is involved in the neuronal damage occurring in MS.

Among chemotherapeutic agents, antitubercular (rifampicin) or antiretroviral (entecavir) drugs tend to up-regulate CD1 expression, whereas zidovudine (AZT), that inhibits iDC proliferation, diminishes the overall availability of $\mathrm{CD} \mathrm{a}^{+}$cells. In the area of antineoplastic therapy, reduction of cytokine-induced CD1 levels by various agents is the dominant finding, as shown in vitro by histone deacetylase (HDAC) inhibitors, tyrosin kinase inhibitors (i.e., imatinib and sorafenib) and antiestrogens, and in vivo by thalidomide in multiple myeloma (MM) patients.

More difficult to interpret is the activity of a classical agent largely utilized in mood disorders including bipolar affective disorders, such as lithium. The drug downregulates the in vitro cytokine-induced CDla expression in MOs of healthy donors. However, limited CD1a expression is elicited by G4 in MOs collected from patients with bipolar disorders. In this case, in vivo treatment of donor patients with lithium restores full responsiveness of their MOs to G4 exposure in vitro.

6.2. Cytokines and Autacoids. Table 3 illustrates the limited information available from the literature on the effect 
TABle 2: Pharmacological modulation of CD1 molecule expression.

\begin{tabular}{|c|c|c|c|c|c|c|}
\hline Drug class & Agent & Therapeutic use & $\mathrm{CD} 1^{\mathrm{a}}$ & $\mathrm{ED}^{\mathrm{b}}$ & $\operatorname{Ref}^{c}$ & Observations \\
\hline $\begin{array}{l}\text { Angiotensin } \\
\text { receptor } \\
\text { antagonists }\end{array}$ & $\begin{array}{l}\text { Losartan } \\
\text { (AT1-R) } \\
\text { PD123319 } \\
(\text { AT2-R) } \\
\end{array}$ & Hypertension & $\begin{array}{l}\mathrm{D} \\
\mathrm{U}\end{array}$ & $\begin{array}{l}\text { ED-1 } \\
\text { ED-1 }\end{array}$ & {$[107]$} & Assay performed on day 7 . \\
\hline Anti-asthma & $\begin{array}{l}\text { Suplatast } \\
\text { tosilate }\end{array}$ & $\begin{array}{l}\text { Inhibitor of } \\
\text { Th-2 responses }\end{array}$ & $\mathrm{D}$ & $\begin{array}{l}\text { ED-1 } \\
\text { ED-2 }\end{array}$ & {$[108]$} & $\begin{array}{l}\text { In ED-1 the assay was performed on day } 7 . \\
\text { DCs were obtained from pts with asthma. }\end{array}$ \\
\hline \multirow{3}{*}{ Anti-depressant } & \multirow{3}{*}{ Lithium } & \multirow{3}{*}{$\begin{array}{l}\text { Bipolar } \\
\text { disorders }\end{array}$} & $\mathrm{D}$ & ED-1 & {$[109]$} & $\begin{array}{l}\text { MOs, obtained from bipolar pts, were } \\
\text { incubated with G4. }\end{array}$ \\
\hline & & & $\mathrm{U}$ & IvDC & [109] & $\begin{array}{l}\text { In vitro generated DCs from lithium-treated } \\
\text { pts showed higher CD1a expression than DCs } \\
\text { from untreated pts. }\end{array}$ \\
\hline & & & $\mathrm{D}$ & ED-1 & {$[110]$} & $\begin{array}{l}\text { Mechanism: CD1 down-regulation is likely } \\
\text { mediated through the GSK- } 3 \beta \text { pathway. }\end{array}$ \\
\hline Anti-estrogens & $\begin{array}{l}\text { Tamoxifen } \\
\text { Toremifene }\end{array}$ & Breast cancer & $\mathrm{D}$ & $\begin{array}{l}\text { ED-1 } \\
\text { ED-2 }\end{array}$ & {$[111]$} & Assay performed on day 7 \\
\hline \multirow{5}{*}{$\begin{array}{l}\text { Anti- } \\
\text { inflammatory } \\
\text { corticosteroids }\end{array}$} & $\begin{array}{l}\text { Beclomethasone } \\
\text { dipropionate } \\
\text { (BDP, inhaled) }\end{array}$ & Asthma & $\mathrm{D}$ & IvDC & {$[112]$} & $\begin{array}{l}\text { In bronchial mucosa of asthmatic pts there is } \\
\text { an increase of CD1a }{ }^{+} \text {DCs. Following } \\
\text { long-term treatment with BDP the number of } \\
\text { CD } 1 \mathrm{a}^{+} \text {DCs went to normal levels of } \\
\text { non-asthmatic pts. }\end{array}$ \\
\hline & \multirow{3}{*}{$\begin{array}{l}\text { Dexamethasone } \\
(\mathrm{DEX})\end{array}$} & \multirow{3}{*}{$\begin{array}{l}\text { Inflammatory } \\
\text { diseases }\end{array}$} & $\mathrm{D}$ & $\begin{array}{l}\text { ED-1 } \\
\text { ED-4 }\end{array}$ & {$[113]$} & $\begin{array}{l}\text { Strong CD1a down-regulation. Mechanism: } \\
\text { high IL-10 via Extracellular signal-regulated } \\
\text { kinases (ERK) phosphorylation. }\end{array}$ \\
\hline & & & \multirow[t]{2}{*}{$\mathrm{D}$} & OED & {$[114]$} & $\begin{array}{l}\text { CD } 34^{+} \text {cord blood stem cells were cultured } \\
\text { with SCS, Flt3-ligand and GM-CSF } \\
\text { (Pre-DC). After } 5 \text { days, TNF } \alpha \text { and IL- } 4 \text { were } \\
\text { added (differentiation stage). On day, } 10 \\
\text { CD-40 ligand and anti-human CD } 40 \text {-ligand } \\
\text { were also added (maturation stage). DEX, } \\
\text { added during differentiation stage, suppresses } \\
\text { CD 1a at the end of the immature (day 10) } \\
\text { and at the mature stage (day 12). On the } \\
\text { contrary, CDla was expressed at normal } \\
\text { levels when DEX exposure was limited to the } \\
2 \text { day maturation stage. }\end{array}$ \\
\hline & & & & $\begin{array}{l}\text { ED-1 } \\
\text { ED-3 } \\
\text { ED-4 }\end{array}$ & {$[115]$} & $\begin{array}{l}\text { The MO-derived DCs were obtained from } \\
\text { neonatal cord and adult blood. }\end{array}$ \\
\hline & $\begin{array}{l}\text { Various } \\
\text { including DEX }\end{array}$ & & $\mathrm{NC}$ & OED & {$[116]$} & $\begin{array}{l}\mathrm{CD} \mathrm{a}^{+} \text {cells derived from bronchoalveolar } \\
\text { lavage showed lower APC function if treated } \\
\text { with DEX in vitro. }\end{array}$ \\
\hline $\begin{array}{l}\text { Anti-tubercular } \\
\text { agents }\end{array}$ & Rifampicin & & $\mathrm{U}$ & ED-1 & $\begin{array}{l}{[117]} \\
{[118]}\end{array}$ & $\begin{array}{l}\text { Test on CD1b: the drug does not affect the } \\
\text { functional activity of the T-cell clone capable } \\
\text { of recognizing the mycolic acid of } M \text {. } \\
\text { tuberculosis origin, presented by CD1b } \\
\text { proteins. } \\
\text { Test on CD1b: effect obtained at clinical } \\
\text { concentration of the drug. }\end{array}$ \\
\hline Antiviral & $\begin{array}{l}\text { AZT } \\
\text { Entecavir }\end{array}$ & $\begin{array}{l}\text { HIV treatment } \\
\text { Hepatitis B } \\
\text { treatment }\end{array}$ & $\begin{array}{l}\mathrm{NC} \\
\mathrm{U}\end{array}$ & $\begin{array}{l}\text { ED-1 } \\
\text { ED-1 }\end{array}$ & $\begin{array}{l}{[119]} \\
{[120]}\end{array}$ & $\begin{array}{l}\text { AZT inhibits DC proliferation, thereby } \\
\text { reducing the total number of DCs. }\end{array}$ \\
\hline Bisphosphonates & Zoledronic acid & Osteoporosis & $\mathrm{D}$ & $\begin{array}{l}\mathrm{ED}-4 \\
\mathrm{ED}-2\end{array}$ & {$[121]$} & $\begin{array}{l}\text { Mechanism: possibly via IL-10 induction, } \\
\text { antagonized by geranylgeraniol. }\end{array}$ \\
\hline
\end{tabular}


Table 2: Continued.

\begin{tabular}{|c|c|c|c|c|c|c|}
\hline Drug class & Agent & Therapeutic use & $\mathrm{CD} 1^{\mathrm{a}}$ & $\mathrm{ED}^{\mathrm{b}}$ & $\operatorname{Ref}^{c}$ & Observations \\
\hline Disinfectants & $\begin{array}{l}\text { Sodium } \\
\text { Chlorate }\end{array}$ & & $\mathrm{D}$ & ED-1 & {$[122]$} & $\begin{array}{l}\text { Sodium chlorate reduces GAG sulfation on } \\
\text { MO surface. Reduction of sulfated CSB } \\
\text { impairs IL- } 4 \text { mediated DC differentiation and } \\
\text { CD1a expression. }\end{array}$ \\
\hline \multirow[t]{2}{*}{ HDAC inhibitors } & $\begin{array}{l}\text { MS-275 Sodium } \\
\text { valproate }\end{array}$ & Antitumor & $\mathrm{D}$ & $\begin{array}{l}\mathrm{ED}-4 \\
\mathrm{ED}-1\end{array}$ & {$[123]$} & $\begin{array}{l}\text { Mechanism: NF- } k \text { B, IRF- } 3 \text { and IRF- } 8 \\
\text { inhibition. Possible use in inflammatory and } \\
\text { autoimmune disorders. }\end{array}$ \\
\hline & Na butyrate & & $\mathrm{D}$ & ED-1 & {$[124]$} & $\begin{array}{l}\text { The agent prevents CD1 upregulation } \\
\text { induced by activation of TLR- } 2 \text {. }\end{array}$ \\
\hline \multirow[t]{2}{*}{$\begin{array}{l}\text { Immuno } \\
\text { stimulant agents }\end{array}$} & $\begin{array}{l}\text { Imiquimod } \\
\text { (imidazo } \\
\text { quinoline) }\end{array}$ & $\begin{array}{l}\text { Topical use in } \\
\text { squamous cell } \\
\text { carcinoma }\end{array}$ & $\mathrm{D}$ & IvDC & {$[125]$} & In skin biopsies after topical treatment. \\
\hline & OK-432 & $\begin{array}{l}\text { In cancer } \\
\text { treatment }\end{array}$ & $\mathrm{U}$ & ED-2 & {$[126]$} & $\begin{array}{l}\text { The maturation step was performed with } \\
\text { OK- } 432 \text { which promotes a higher expression } \\
\text { of CD1a in respect to that obtained with LPS. }\end{array}$ \\
\hline \multirow{12}{*}{$\begin{array}{l}\text { Immuno } \\
\text { suppressive } \\
\text { agents }\end{array}$} & $\begin{array}{l}\text { Gold sodium } \\
\text { thiomalate } \\
\text { (GST) }\end{array}$ & $\begin{array}{l}\text { Rheumatoid } \\
\text { arthritis (RA) }\end{array}$ & $\mathrm{D}$ & $\begin{array}{l}\text { ED-1 } \\
\text { ED-2 } \\
\text { ED-4 }\end{array}$ & {$[127]$} & $\begin{array}{l}\text { DCs were obtained from healthy donors or } \\
\text { RA pts. The suppression of DC differentiation } \\
\text { and function might explain the in vivo effect } \\
\text { of GST on RA patients. }\end{array}$ \\
\hline & $\begin{array}{l}\text { Glatiramer } \\
\text { acetate }(\mathrm{GA})+ \\
\text { minocycline } \\
(\mathrm{MIN})\end{array}$ & $\begin{array}{l}\text { Multiple } \\
\text { sclerosis (MS) }\end{array}$ & $\mathrm{D}$ & $\begin{array}{l}\text { ED-1 } \\
\text { ED-4 }\end{array}$ & {$[128]$} & $\begin{array}{l}\text { DCs were obtained from untreated and } \\
\text { GA-treated MS pts. The possible additive } \\
\text { effects of GA and MIN on MO-derived DCs, } \\
\text { seem to support the use of such combination } \\
\text { therapy in MS. }\end{array}$ \\
\hline & $\mathrm{GA}+\mathrm{IFN} \beta$ & MS & $\mathrm{D}$ & IvDC & {$[129]$} & $\begin{array}{l}\text { MOs were obtained from untreated or treated } \\
\text { MS pts and from healthy donors. } \\
\text { Combination therapy with IFN } \beta+\text { GA } \\
\text { resulted in a more pronounced decrease of } \\
\text { circulating CDla compared to monotherapy } \\
\text { with IFN } \beta \text {. }\end{array}$ \\
\hline & & MS & $\mathrm{D}$ & ED-1 & {$[130]$} & $\begin{array}{l}\text { Assay was performed on day } 7 . \text { DC were } \\
\text { obtained from MS pts. Synergistic effects of } \\
\text { GA and IFN } \beta \text {. }\end{array}$ \\
\hline & $\begin{array}{l}\text { Monomethyl- } \\
\text { fumarate } \\
(\mathrm{MMF})\end{array}$ & Psoriasis & $\mathrm{D}$ & $\begin{array}{l}\text { ED-1 } \\
\text { ED-4 }\end{array}$ & {$[131]$} & $\begin{array}{l}\text { MMF interfered with the MO-derived DC } \\
\text { differentiation, resulting in impaired } \\
\text { maturation of these cells. }\end{array}$ \\
\hline & Pimecrolimus & $\begin{array}{l}\text { Atopic } \\
\text { dermatitis }\end{array}$ & $\mathrm{NC}$ & ED-1 & {$[132]$} & $\begin{array}{l}\text { No interference with the function of DCs, } \\
\text { whereas the activation of effector T-cells was } \\
\text { inhibited. }\end{array}$ \\
\hline & & & $\mathrm{U}$ & IvDC & {$[133]$} & $\begin{array}{l}\text { In epidermal cells (biopsy) after topical } \\
\text { treatment. }\end{array}$ \\
\hline & Rapamycin & Immuno- & $\mathrm{U}$ & $\begin{array}{l}\mathrm{ED}-1 \\
\mathrm{ED}-4\end{array}$ & {$[134]$} & $\begin{array}{l}\text { Reduction of MHC-I, MHC-II and Ag } \\
\text { uptake. }\end{array}$ \\
\hline & Sinomenine & suppressant & $\mathrm{U}$ & ED-1 & {$[135]$} & $\begin{array}{l}\text { The drug prevents LPS-induced DC } \\
\text { maturation. }\end{array}$ \\
\hline & $\begin{array}{l}\text { Tacrolimus } \\
\text { (FK506) }\end{array}$ & & $\mathrm{D}$ & $\begin{array}{l}\text { ED-1 } \\
\text { ED-2 } \\
\text { ED-4 }\end{array}$ & {$[136]$} & Effect on LPS-induced DCs in vitro. \\
\hline & & & $\mathrm{D}$ & IvDC & {$[137]$} & $\begin{array}{l}\text { Topical treatment of epidermal } \mathrm{CD} \mathrm{a}^{+} \text {, in pts } \\
\text { with atopic dermatitis. }\end{array}$ \\
\hline & & & $\mathrm{U}$ & OED & {$[138]$} & $\begin{array}{l}\text { Generation of DCs from CD } 34^{+} \text {peripheral } \\
\text { blood progenitors obtained by culturing the } \\
\text { cells with GM-CSF, TNF } \alpha \text {, stem cell factor for } \\
14 \text { days. FK } 506 \text { was added throughout the } \\
\text { culture starting on day } 0 .\end{array}$ \\
\hline
\end{tabular}


Table 2: Continued.

\begin{tabular}{|c|c|c|c|c|c|c|}
\hline Drug class & Agent & Therapeutic use & $\mathrm{CD} 1^{\mathrm{a}}$ & $\mathrm{ED}^{\mathrm{b}}$ & $\operatorname{Ref}^{\mathrm{c}}$ & Observations \\
\hline & Triptolide & $\begin{array}{l}\text { Polycystic } \\
\text { Kidney disease }\end{array}$ & $\mathrm{D}$ & $\begin{array}{l}\text { ED-1 } \\
\text { ED-2 }\end{array}$ & {$[139]$} & $\begin{array}{l}\text { Suppression of DC differentiation and } \\
\text { maturation by triptolide may explain some of } \\
\text { its immunosuppressive properties. }\end{array}$ \\
\hline Insecticides & Rotenone & & $\mathrm{D}$ & ED-1 & {$[140]$} & $\begin{array}{l}\text { Mechanism: increased levels of reactive } \\
\text { oxygen species that seem to trigger the } \\
\text { differentiation process of DC. }\end{array}$ \\
\hline \multirow{2}{*}{$\begin{array}{l}\text { Multidrug } \\
\text { resistance (MDR) } \\
\text { protein } \\
\text { antagonists }\end{array}$} & \multirow{2}{*}{$\begin{array}{l}\text { MK571[multi } \\
\text { drug resistance } \\
\text { protein } 1 \\
\text { (MRP1) } \\
\text { blocker] } \\
\text { PSC833 (P-gp } \\
\text { blocker) }\end{array}$} & \multirow[t]{2}{*}{$\begin{array}{l}\text { Possible use in } \\
\text { MDR }\end{array}$} & $\mathrm{D}$ & $\mathrm{ED}-4$ & {$[141]$} & $\begin{array}{l}\text { MRP1 transporter activity is important for } \\
\text { DC differentiation. }\end{array}$ \\
\hline & & & $\mathrm{NC}$ & OED & & $\begin{array}{l}\text { Langerhans-like DCs were obtained from } \\
\text { human acute myeloid leukemia cell line } \\
\text { MUTZ-3, cultured with TGF- } \beta 1, \text { GM-CSF } \\
\text { and TNF } \alpha \text { for } 10 \text { days, and MDR antagonists } \\
\text { were added on day } 4,7 \text {, and } 10 .\end{array}$ \\
\hline $\begin{array}{l}\text { Monoclonal } \\
\text { antibodies }\end{array}$ & Infliximab & Anti-TNF $\alpha$ & $\mathrm{D}$ & $\begin{array}{l}\text { ED-1 } \\
\text { ED-4 }\end{array}$ & {$[142]$} & $\begin{array}{l}\text { MOs from psoriasis pts. Reduction of } \\
\text { antigen-presenting capacity of DCs, } \\
\text { proliferation and IFN } \gamma \text { release by psoriatic } \\
\text { T-cells. }\end{array}$ \\
\hline \multirow[t]{2}{*}{ NSAID } & $\begin{array}{l}\text { Acetylsalicylic } \\
\text { acid (ASA) }\end{array}$ & Inflammation & $\mathrm{D}$ & $\begin{array}{l}\text { ED-1 } \\
\text { ED-4 }\end{array}$ & {$[143]$} & $\begin{array}{l}\text { The new nitric oxide releasing-ASA } \\
\text { (NCX-4040, NCX-4016) did not affect the } \\
\text { expression of CD1a during maturation stage } \\
\text { (ED-4). }\end{array}$ \\
\hline & $\begin{array}{l}\text { Niflumic acid } \\
\text { (NFA) }\end{array}$ & Inflammation & $\mathrm{D}$ & ED-4 & {$[144]$} & $\begin{array}{l}\text { NFA inhibits LPS-induced DC maturation by } \\
\text { inhibiting co-stimulatory molecule } \\
\text { expression and IL- } 12 \text { p } 70 \text { production. }\end{array}$ \\
\hline $\begin{array}{l}\text { Microsomal } \\
\text { triglyceride } \\
\text { transfer protein } \\
\text { (MTP) inhibitors }\end{array}$ & BMS212122 & Anti-lipid & $\mathrm{D}$ & ED-1 & {$[145]$} & $\begin{array}{l}\text { MTP inhibitors down-regulate self as well as } \\
\text { exogenous lipid antigen presentation. }\end{array}$ \\
\hline NO donors & $\begin{array}{l}\text { DEA-NO, } \\
\text { SIN-1, } \\
\text { DETA-NO }\end{array}$ & & $\begin{array}{l}\mathrm{U} \\
\mathrm{NC}\end{array}$ & $\begin{array}{l}\text { ED-1 } \\
\text { ED-2 } \\
\text { ED-1 }\end{array}$ & {$[146]$} & The drugs are TNF $\alpha$ receptor inhibitors. \\
\hline \multirow[t]{2}{*}{ Statins } & Atorvastatin & Dyslipidemia & $\mathrm{U}$ & OED & {$[147]$} & $\begin{array}{l}\text { MO-derived DCs were obtained from healthy } \\
\text { donors. MOs exposed to atorvastatin in } \\
\text { combination with IFN } \alpha \text {, showed an increased } \\
\text { levels of CD } 1 \text { a compared to IFN } \alpha \text { alone. }\end{array}$ \\
\hline & Lovastatin & & $\mathrm{D}$ & ED-2 & {$[148]$} & $\begin{array}{l}\text { DCs were obtained from MS pts. Lovastatin } \\
\text { was added after G4, simultaneously with } \\
\text { TNF } \alpha \text {. }\end{array}$ \\
\hline TLR agonists & $\begin{array}{l}\text { Pam CSK } \\
\text { resiquimod } \\
(\mathrm{R} 848)\end{array}$ & $\begin{array}{l}\text { Immune } \\
\text { response } \\
\text { modifier }\end{array}$ & $\mathrm{U}$ & OED & [149] & $\begin{array}{l}\text { Induction of } \mathrm{CD}^{+} \mathrm{a}^{+} \text {cells in freshly isolated } \\
\mathrm{BM} \mathrm{CD} 34^{+} \text {progenitor cells cultured with } \\
\text { TLR agonists without cytokines. }\end{array}$ \\
\hline \multirow{4}{*}{$\begin{array}{l}\text { Tyrosine Kinase } \\
\text { Inhibitors }\end{array}$} & Imatinib & Antitumor & $\mathrm{D}$ & $\begin{array}{l}\text { ED-1 } \\
\text { ED-4 }\end{array}$ & {$[150]$} & $\begin{array}{l}\text { In ED-1 the assay was performed on day } 7 . \\
\text { Mechanism: NF- } k \text { B and AKT inhibition. }\end{array}$ \\
\hline & & & $\mathrm{D}$ & OED & {$[151]$} & $\begin{array}{l}\text { In vitro effects of imatinib, added to the } \\
\text { culture together with different cytokines, on } \\
\text { the development of mobilized human CD } 34^{+} \\
\text {peripheral blood progenitor cells into DCs. }\end{array}$ \\
\hline & \multirow[t]{2}{*}{ Sorafenib } & \multirow[t]{2}{*}{ Antitumor } & \multirow[t]{2}{*}{$\mathrm{D}$} & ED-1 & {$[152]$} & In ED-1 sorafenib was added on day 5. \\
\hline & & & & ED-2 & & Mechanism: P13MAPK and NF- $k$ B inhibition. \\
\hline Various & $\begin{array}{l}\text { All } \\
\text { trans-retinoic } \\
\text { acid (ATRA) }\end{array}$ & Various & $\mathrm{U}$ & ED-1 & {$[153]$} & $\begin{array}{l}\text { In ED-1 ATRA was associated with GM-CSF } \\
\text { without IL-4. }\end{array}$ \\
\hline
\end{tabular}


Table 2: Continued.

\begin{tabular}{|c|c|c|c|c|c|c|}
\hline Drug class & Agent & Therapeutic use & $\mathrm{CD} 1^{\mathrm{a}}$ & $\mathrm{ED}^{\mathrm{b}}$ & $\operatorname{Ref}^{c}$ & Observations \\
\hline & $\begin{array}{l}\text { Retinoic acid } \\
(\text { Am80) }\end{array}$ & Various & $\mathrm{D}$ & ED-1 & {$[154]$} & $\begin{array}{l}\text { Am } 80 \text { treatment ameliorated macro- and } \\
\text { microscopic damage in dextran sodium } \\
\text { sulfate-induced colitis in mice, and } \\
\text { suppressed the colitis induced elevation of } \\
\text { IL-12. }\end{array}$ \\
\hline & Thalidomide & $\begin{array}{l}\text { Multiple } \\
\text { myeloma (MM) }\end{array}$ & $\mathrm{D}$ & OED & {$[155]$} & $\begin{array}{l}\text { MOs were obtained from peripheral blood of } \\
\text { MM pts treated or not with thalidomide. For } \\
\text { in vitro DCs generation standard cytokines } \\
\text { were used. }\end{array}$ \\
\hline & & Sarcoidosis & $\mathrm{U}$ & IvDC & {$[156]$} & $\begin{array}{l}\text { In skin biopsies of sarcoidosis pts treated or } \\
\text { not with thalidomide. }\end{array}$ \\
\hline & $\begin{array}{l}\text { Trimethyl } \\
\text { psoralen }+ \\
\text { PUVA }\end{array}$ & Psoriasis & $\mathrm{D}$ & IvDC & {$[157]$} & $\begin{array}{l}\text { Biopsies of lesional skin were performed in } \\
\text { pts with psoriasis, before treatment, after } 2 \\
\text { weeks of treatment or at the end of treatment. }\end{array}$ \\
\hline & $\begin{array}{l}\text { Dehydro- } \\
\text { epiandro- } \\
\text { sterone }\end{array}$ & & $\mathrm{D}$ & ED-1 & {$[158]$} & $\begin{array}{l}\text { Slight down-regulation. The assay was } \\
\text { performed on day } 7 \text {. Reduction of IL-10 } \\
\text { (opposite effect respect to DEX). }\end{array}$ \\
\hline & $\begin{array}{l}\text { Terpenes: } \\
\text { Calamenene } \\
\text { T-cadinol }\end{array}$ & $\begin{array}{l}\text { Anti- } \\
\text { inflammatory, } \\
\text { anti-septic }\end{array}$ & $\mathrm{U}$ & ED-2 & {$[159]$} & \\
\hline & $\begin{array}{l}\text { Terpenes: } \\
\text { Epicubenol, } \\
\text { Ferruginol }\end{array}$ & Anti-septic & $\mathrm{U}$ & OED & {$[160]$} & $\begin{array}{l}\text { MOs were cultured with G4, followed by } \\
\text { another } 2 \text { days with the drugs. Surprisingly } \\
\text { both induce IL-10 generating Treg. }\end{array}$ \\
\hline & $\begin{array}{l}\text { Piceatannol } \\
\text { (stilbene } \\
\text { derivative) }\end{array}$ & $\begin{array}{l}\text { Anti- } \\
\text { inflammatory, } \\
\text { immunomodu- } \\
\text { latory and } \\
\text { anti- } \\
\text { proliferative }\end{array}$ & $\mathrm{U}$ & OED & {$[161]$} & $\begin{array}{l}\text { MOs were cultured with G4 for } 6 \text { days, } \\
\text { followed by another } 2 \text { days in the presence of } \\
\text { piceatannol alone. On the contrary high } \\
\text { concentration of resveratrol, another stilbene } \\
\text { derivative, markedly reduces CD } 1 \text { b } \\
\text { expression on G4-induced iDCs (Fuggetta et } \\
\text { al., in preparation). }\end{array}$ \\
\hline Vegetal products & $\begin{array}{l}\text { Ginseng } \\
\text { saponins (M1 } \\
\text { and M4) }\end{array}$ & Various & $\mathrm{U}$ & ED-2 & {$[162]$} & $\begin{array}{l}\text { After G4 DCs were treated on day } 6 \text { only with } \\
\text { M1 or M4. }\end{array}$ \\
\hline \multirow{7}{*}{ Vitamins } & \multirow{6}{*}{$\begin{array}{l}\text { Alpha dihydroxy } \\
\text { vitamin D3 }\end{array}$} & \multirow{6}{*}{ MS } & $\mathrm{D}$ & ED-1 & {$[163]$} & 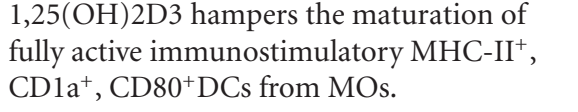 \\
\hline & & & $\mathrm{D}$ & $\begin{array}{l}\text { ED-1 } \\
\text { OED }\end{array}$ & {$[164]$} & $\begin{array}{l}\text { CD } 34^{+} \text {cells were collected by apheresis either } \\
\text { from cancer pts after chemotherapy or from } \\
\text { healthy donors after G-CSF treatment. For } \\
\text { DC generation the cells were cultured with } \\
\text { standard cytokines. }\end{array}$ \\
\hline & & & $\mathrm{D}$ & ED-2 & {$[165]$} & $\begin{array}{l}\text { DCs were obtained from MS pts. Beneficial } \\
\text { action of vitamin D in MS may be associated } \\
\text { with its inhibition on both differentiation and } \\
\text { maturation of DCs. }\end{array}$ \\
\hline & & & $\mathrm{D}$ & ED-4 & {$[166]$} & $\begin{array}{l}\text { Accompanied by overexpression of miR- } 378 \\
\text { and low expression of miR- } 155 \text { that could } \\
\text { have a role in DC function. }\end{array}$ \\
\hline & & & $\mathrm{D}$ & ED-1 & {$[167]$} & $\begin{array}{l}\text { D3 up-regulates colony stimulating factor } 1 \\
\text { and downregulates its receptors. }\end{array}$ \\
\hline & & & $\mathrm{D}$ & ED-1 & {$[168]$} & $\begin{array}{l}\text { Assay was performed on day } 7 \text {. Inhibition of } \\
\text { DC differentiation and maturation. }\end{array}$ \\
\hline & $\begin{array}{l}\text { Calcipotriol } \\
\text { (vit. D3 analog) }\end{array}$ & $\begin{array}{l}\text { Topical in } \\
\text { psoriasis }\end{array}$ & $\mathrm{D}$ & OED & {$[169]$} & In vivo treated psoriatic skin. \\
\hline
\end{tabular}

${ }^{\mathrm{a}}$ Evaluation of CDla expression if not otherwise specified: U: upregulation; D: down-regulation; NC: no change.

${ }^{b}$ Experimental design code (see Figure 2).

${ }^{c}$ Reference number. 
of prostaglandins and serotonin on CD1a expression in different experimental conditions in vitro. In all cases, the agents show suppressive activity.

When cytokines are considered, GM-CSF and IL-4 are not enlisted in Table 3. Actually, this cytokine combination is used by most of in vitro tests, to induce iDCs that express high levels of CD1 proteins (Figures 1 and 2). In particular, GM-CSF is the most potent inducer, whereas IL-4 reinforces the effect of GM-CSF but is scarcely active if used alone.

A number of data from the literature is presently available on IFNs that show predominant inhibitory effects on CD1 system. While IFN $\alpha$ can be involved in the transition from iDCs to mDCs (Figure 1), IFN $\beta$ downregulates CD1 protein expression either in vivo or in vitro. In addition this cytokine was found to reduce the functional activity of mDCs. Since IFN $\beta$ has acquired a definite role in MS treatment, these results add further support to the hypothesis of the involvement of CD1 system in MS pathogenesis.

Consistent inhibitory effects on CD1 expression are manifested by IL- 6 and IL-10 in various experimental conditions. It must be pointed out that in many cases down-regulation of G4-induced CD1 expression provoked by various agents appears to be mediated by the release of IL- 6 and more frequently by the release of IL-10 that operates according to an autocrine pattern.

Of interest, finally is the mechanism by which TGF $\beta$ appears to maintain CD1a expression on LC generated in vitro from purified $\mathrm{CD}_{3} 4^{+}$cells. In this case, the expression of CD1a, that is normally found to be elevated in immature LCs, declines with LC maturation. Since TGF $\beta$ prevents LC maturation, it allows the long-term presence of high CD1a levels in LCs.

6.3. Biological and Physical Agents. With the exception of the placental growth factor, all biological and physical agents illustrated in Table 4 provoke down-regulation of cytokineinduced CD1 protein expression. The mechanism underlying the effect of various lipids including some contained in human serum, indicates a common target consisting in peroxisome proliferator-activated receptor $(\mathrm{PPAR}) \gamma$ that appears to be activated by these molecules in various experimental conditions. The observation that human serum, either for the presence of different lipoproteins or for the presence of IgG and $\beta 2$-microglobulin (Table 4), provides inhibitory effects, poses undoubtedly the question of the efficiency of the CD1 system in vivo in infected patients.

Of considerable interest is the finding that various supernatants of human tumor cell cultures contain inhibitory factors. Although mycoplasma contamination of cultured cells could be, at least in part, responsible for these findings (see Table 5), it cannot be excluded that this type of suppression of antigen-presenting function could be of relevance in tumor-induced immune suppression.

The in vivo impairment of CD1a expression by ultraviolet light is not surprising, since the general immune-suppressive effects of this type of radiation has been demonstrated in different effector functions of the immune system.
6.4. Infectious Agents or Microorganism Products. In vitro and in vivo studies concerning modulation of CD1 system by bacterial and chlamydial infections generally demonstrated a CD1 upregulation (Table 5). It is reasonable to speculate that, in certain experimental conditions, TLR-2 activation by microorganisms could be involved [29]. Surprisingly, however, is the finding that antral biopsies performed in $H$. pilori-infected children reveal $\mathrm{CD} 1 \mathrm{a} / \mathrm{b}$ upregulation respect to normal subjects, whereas in vitro exposure of MOs to formalin-killed $H$. pilori prevents CD1 induction by G4.

Of particular note is the finding that CDla is upregulated in vitro by G4 more vigorously in MOs obtained from MS patients bearing an infectious disease, with respect to MOs obtained from noninfected MS patients. This observation has been put in relationship with the clinical finding that subjects affected by MS are at particular risk of relapse in the course of bacterial infections. Again, this seems to provide support to the hypothesis of a significant role that could be played by CD1 system in MS.

Differently from the in vivo and in vitro effect of the bacteria and chlamydia reported in Table 5, infections with various protozoa, with at least two types of helminthes, and viruses such as HHV-8 and Cytomegalovirus leads to impairment of CD1 expression in various types of experimental design. This is not surprising since the general immunodepressive activity of these infections has been known for several years.

When microorganism products are considered, only attenuated Dengue-2 live vaccine, malaria-associated AMA1 , and staphylococcus superantigen are able to up-regulate cytokine-induced CD1 expression. Toxins and malaria hemozoin provide opposite effects on the system. A particular feature that distinguishes the activity of pertussis toxin from the other microorganism products resides in its unusual property of suppressing CD1a expression selectively, without reducing the levels of the other components of the system (i.e., CD1b and CD1c). It is not excluded that this could allow selective analysis of $C D 1 A$ gene regulation distinct from that of the other $C D 1$ genes.

Finally, of relevance is the finding that LPS is able to down-regulate G4-induced CD1a. LPS, that is considered the standard agent for generating mDCs from iDCs (Figures 1 and 2), is a common constituent of pathogenic or nonpathogenic microorganisms, being present in the cell wall of gram-negative bacteria. Therefore, it is reasonable to consider that this molecule could play a significant role in the clinic, possibly through its modulating activity on CD1 expression and DC maturation.

\section{Conclusions and Perspectives}

Fine tuning of biological functions governed by a complex signaling network is commonly seen in living organisms, and the CD1 system does not represent an exception to this rule. This opens up several options to intentionally manipulate the CD1 expression in order to enhance or depress antigenic lipid presentation according to the therapeutic needs. The results of the literature analysis presented here clearly demonstrate that a large variety of different externally acting agents, 
TABLE 3: Effect of autacoids or cytokines on CD1 molecule expression.

\begin{tabular}{|c|c|c|c|c|}
\hline Molecule & $\mathrm{CD} 1^{\mathrm{a}}$ & $\mathrm{ED}^{\mathrm{b}}$ & Ref. $^{c}$ & Observations \\
\hline \multicolumn{5}{|l|}{ Autacoids } \\
\hline \multirow{8}{*}{$\begin{array}{l}\text { Prostaglandin } \\
\text { PGE }_{2}\end{array}$} & $\mathrm{D}$ & ED-4 & {$[170]$} & \multirow{8}{*}{$\begin{array}{l}\text { Purified CD } 14^{+} \text {cells from PB of healthy } \\
\text { donors mobilized with G-CSF for allogeneic } \\
\text { transplantation. }\end{array}$} \\
\hline & $\mathrm{D}$ & ED-1 & {$[171]$} & \\
\hline & $\mathrm{D}$ & ED-2 & & \\
\hline & $\mathrm{LD}$ & ED-3 & & \\
\hline & $\mathrm{D}$ & ED-4 & & \\
\hline & $\mathrm{D}$ & ED-1 & {$[172]$} & \\
\hline & $\mathrm{D}$ & ED-1 & {$[173]$} & \\
\hline & $\mathrm{D}$ & ED-1 & {$[174]$} & \\
\hline $\begin{array}{l}\text { Cyclopentenone } \\
\text { Prostaglandins } \\
\text { (CP) (15d-PGJ2, } \\
\text { 12-PGJ2, PGA2, } \\
\text { PGD2, and PGE2) }\end{array}$ & $\mathrm{D}$ & ED-1 & {$[175]$} & $\begin{array}{l}\text { MOs + G4 for } 7 \text { days. CP were added during } \\
\text { the last } 24 \text { h of culture without adding } \\
\text { maturation factors. In these experimental } \\
\text { conditions, CP induced apoptosis. }\end{array}$ \\
\hline $\begin{array}{l}\text { Serotonin } \\
\text { (5-hydroxy- } \\
\text { tryptamine, } \\
\text { 5-HT) }\end{array}$ & $\begin{array}{l}\mathrm{D} \\
\mathrm{D}\end{array}$ & $\begin{array}{l}\text { ED-1 } \\
\text { ED-4 }\end{array}$ & {$[176]$} & $\begin{array}{l}\text { MOs. } 5 \text {-HT effects mediated via } 5-\mathrm{HTR}_{1 / 7} \\
\text { iDCs and mDCs exposed to } 5 \text {-HT for } 24 \mathrm{~h} \\
\text { did not show alteration of CDla expression. }\end{array}$ \\
\hline \multicolumn{5}{|l|}{ Cytokines } \\
\hline $\operatorname{IFN} \alpha 2 \mathrm{a}$ & $\mathrm{D}$ & OED & {$[177]$} & $\begin{array}{l}\text { MOs cultured for } 7 \text { days with } \\
(\text { GM-CSF+IL-4+TNF- } \alpha)+/- \text { IFN } \alpha 2 \text { a. }\end{array}$ \\
\hline IFN $\alpha 2 b$ & $\mathrm{D}$ & OED & {$[178]$} & $\begin{array}{l}\text { MOs cultured with GM-CSF +/- IFN } \alpha 2 b \\
\text { for } 5 \text { days. }\end{array}$ \\
\hline $\begin{array}{l}\text { IFN } \alpha+\text { IL- } 2 \text { or } \\
\text { IL- } 12 \text { alone }\end{array}$ & $\mathrm{NC}$ & $\begin{array}{l}\text { IvDC } \\
\text { OED }\end{array}$ & {$[179]$} & $\begin{array}{l}\text { MOs obtained from PB of pts with renal cell } \\
\text { cancer before, during, and after therapy } \\
\text { with the indicated cytokines, or from } \\
\text { healthy subjects were cultured with G4 for } 8 \\
\text { days. The yield of DCs from cancer pts was } \\
\text { lower than that from healthy subjects. } \\
\text { However, the phenotype of DCs generated } \\
\text { from MO of pts was comparable to that of } \\
\text { DCs generated from MO of healthy subjects. }\end{array}$ \\
\hline \multirow{6}{*}{ IFN $\beta 1 \mathrm{a}$} & $\mathrm{D}$ & ED-2 & {$[148]$} & MOs from PB of untreated pts with MS. \\
\hline & $\mathrm{D}$ & ED-1 & {$[180]$} & $\begin{array}{l}\text { MOs from PB of untreated or } \\
\text { IFN } \beta \text { 1a-treated pts with MS. }\end{array}$ \\
\hline & $\mathrm{D}$ & ED-4 & {$[181]$} & $\begin{array}{l}\text { MOs from PB of untreated pts with MS. } \\
\text { Analysis was performed on CD1a/b/c } \\
\text { molecules. }\end{array}$ \\
\hline & $\mathrm{D}$ & ED-1 & {$[182]$} & \\
\hline & $\mathrm{D}$ & IvDC & [183] & $\begin{array}{l}\text { Evaluation of } \% \text { of } \mathrm{CD} 1 \mathrm{a}^{+} \mathrm{HLA}-\mathrm{DR}^{+} \mathrm{MNC} \\
\text { in PB of MS pts, either untreated or treated } \\
\text { with IFN } \beta 1 \mathrm{a} \text {, and in healthy subjects. }\end{array}$ \\
\hline & $\mathrm{D}$ & ED-4 & {$[184]$} & $\begin{array}{l}\text { Purified CD } 14^{+} \text {cells from PB of healthy } \\
\text { subjects. }\end{array}$ \\
\hline IFN $\beta 1 b$ & $\mathrm{D}$ & ED-1 & {$[185]$} & $\begin{array}{l}\text { MOs from PB of untreated or } \\
\text { IFN } \beta 1 \text { a-treated pts with MS and from } \\
\text { healthy subjects. }\end{array}$ \\
\hline IFN $\gamma$ & $\mathrm{D}$ & ED-1 & $\begin{array}{c}{[186} \\
187]\end{array}$ & MOs + G4 for 12 days. \\
\hline Il- $1 \beta$ & $\mathrm{NC}$ & ED-1 & [188] & \\
\hline
\end{tabular}


Table 3: Continued.

\begin{tabular}{|c|c|c|c|c|}
\hline Molecule & $\mathrm{CD} 1^{\mathrm{a}}$ & $\mathrm{ED}^{\mathrm{b}}$ & Ref. $^{c}$ & Observations \\
\hline IL-3 & $\mathrm{U}$ & OED & [189] & $\begin{array}{l}\mathrm{CD}_{14}^{+} \text {osteoclast precursors from PB of } \\
\text { healthy donors cultured with (M-CSF+ } \\
\text { RANKL) +/- IL-3 for } 7 \text { days. }\end{array}$ \\
\hline $\begin{array}{l}\text { IL-6 } \\
\text { sIL-6R } \alpha / \text { IL-6 } \\
\text { fusion protein } \\
\text { (FP6) }\end{array}$ & $\begin{array}{l}\mathrm{D} \\
\mathrm{D}\end{array}$ & OED & [190] & $\begin{array}{l}\mathrm{GPA}^{-} \mathrm{CD} 15^{-} \mathrm{CD} 14^{-} \mathrm{CD} 1 \mathrm{a}^{-} \mathrm{IL}-6 \mathrm{R}^{+} \text {myeloid } \\
\text { progenitors (generated after incubation of } \\
\text { cord blood-derived CD } 34^{+} \mathrm{CD} 38^{-} \text {cells with } \\
\text { SCF+FLT3-L+TPO+IL-3 for } 6-7 \text { days) were } \\
\text { cultured with (SCF+FLT3-L+TPO+IL-3) } \\
+/- \text { IL-6 or FP6 for } 11-14 \text { days. }\end{array}$ \\
\hline $\begin{array}{l}\text { IL-6 } \\
\text { sIL-6R/IL-6 fusion } \\
\text { protein (FP6) }\end{array}$ & $\begin{array}{l}\mathrm{D} \\
\mathrm{D}\end{array}$ & OED & $\begin{array}{c}{[191} \\
192]\end{array}$ & $\begin{array}{l}\mathrm{CD}^{-} 6^{-} \mathrm{CD} 15^{-} \mathrm{CD} 14^{-} \mathrm{CD} 1 \mathrm{a}^{-} \mathrm{IL}-6 \mathrm{R}^{+} \text {myeloid } \\
\text { progenitors (generated after incubation of } \\
\text { cord blood-derived CD } 34^{+} \mathrm{CD} 38^{-} \text {cells with } \\
\text { SCF+FLT3-L+TPO+IL-3 for } 7 \text { days) were } \\
\text { cultured with (SCF+FLT3-L+TPO+IL-3) } \\
+/- \text { IL-6 or FP6 for } 7 \text { days. }\end{array}$ \\
\hline \multirow[t]{2}{*}{ IL-6 } & $\mathrm{D}$ & OED & [193] & $\begin{array}{l}\text { Purified CD } 34^{+} \text {hematopoietic progenitor } \\
\text { cells from PB of G-CSF-treated Pts with } \\
\text { MM were cultured with } \\
\text { (FLT3-L+TNF } \alpha+\text { GM-CSF+SCF+IL- } 4 \text { ) +/- } \\
\text { IL- } 6 \text { (added on day } 0 \text { or day } 7 \text { of culture) for } \\
14 \text { days. CD1a evaluation on day } 14 \text {. }\end{array}$ \\
\hline & $\mathrm{D}$ & ED-1 & [194] & $\begin{array}{l}\text { MOs. Mechanism, Il-6-induced expression } \\
\text { of G-CSF receptor. }\end{array}$ \\
\hline \multirow{3}{*}{ IL-10 } & $\mathrm{D}$ & IvED & [195] & $\begin{array}{l}\text { Psoriatic skin after systemic IL-10 } \\
\text { administration. }\end{array}$ \\
\hline & $\mathrm{D}$ & OED & [196] & $\begin{array}{l}\text { MOs cultured with (GM-CSF+IL-13) +/- } \\
\text { IL-10 for } 7 \text { days. }\end{array}$ \\
\hline & $\mathrm{D}$ & OED & [197] & $\begin{array}{l}\text { MOs cultured with (GM-CSF+IL-13) +/- } \\
\text { IL-10 for } 7 \text { days. }\end{array}$ \\
\hline IL-13 & $\mathrm{U}$ & OED & {$[198]$} & $\begin{array}{l}\text { MOs cultured with G4 or with } \\
\text { GM-CSF+IL- } 13 \text { for } 7 \text { days. Higher CD1a } \\
\text { upregulation with GM-CSF+IL-13. } \\
\text { MOs cultured with G4 for } 7 \text { d and then with } \\
\text { IL- } 13 \text { or TNF } \alpha \text { or IL- } 4 \text { for } 48 \text { h. IL- } 13 \text { as } \\
\text { affective as TNF } \alpha \text { in inducing maturation of } \\
\text { imDC. }\end{array}$ \\
\hline Platelet factor 4 & $\mathrm{D}$ & ED-1 & [199] & \\
\hline TGF- $\beta 1$ & $\mathrm{U}$ & OED & [200] & $\begin{array}{l}\text { Purified CD } 34^{+} \text {hematopoietic progenitor } \\
\text { cells from cord blood cultured with } \\
\text { (FLT3-L+TNF } \alpha+\text { GM-CSF+SCF) +/- TGF- } \\
\beta 1 \text { for } 10-14 \text { days. Cells generated in the } \\
\text { presence of TGF- } \beta 1 \text { resemble immature LC } \\
\text { with high CD1a antigen expression. } \\
\text { Mechanism: maturation of LC leading to } \\
\text { CD1a down-regulation is prevented by } \\
\text { elevated E-cadherin expression induced by } \\
\text { TGF- } \beta 1 \text {. }\end{array}$ \\
\hline
\end{tabular}

${ }^{\mathrm{a}}$ Evaluation of CDla expression if not otherwise specified: D: down-regulation; U: upregulation; LD: limited down-regulation; NC: no changes.

${ }^{\mathrm{b}}$ Experimental design code (see Figure 2).

${ }^{\mathrm{c}}$ Reference number.

either of synthetic or natural origin, can affect profoundly the expression levels of $\mathrm{CD} 1$ glycoproteins, with a possible consequence on DC-mediated lipid presentation to T-cells. Actually, Group I CD1 glycoproteins are mainly involved in the presentation of $M$. tuberculosis-derived lipids to CD1-restricted T-cells. Pharmacological amplification of the system could provide a significant help for vaccination and treatment modalities concerning millions of subjects presently exposed to tuberculosis threat. In particular, the rapidly expanding area of small RNAs capable of controlling directly or indirectly the expression level of an extremely high numbers of genes, could be carefully considered for 
TABLE 4: Effect of biological or physical agents on CD1 molecule expression.

\begin{tabular}{|c|c|c|c|c|c|}
\hline $\begin{array}{l}\text { Type of biological } \\
\text { agents }\end{array}$ & Agent & $\mathrm{CD} 1^{\mathrm{a}}$ & $\mathrm{ED}^{\mathrm{b}}$ & Ref. $^{c}$ & Observations \\
\hline Growth factors & $\begin{array}{l}\text { Placental growth } \\
\text { factor (PLGF) }\end{array}$ & $\mathrm{U}$ & ED-2 & {$[201]$} & $\begin{array}{l}\text { Modest upregulation. PLGF antagonizes } \\
\text { LPS-induced down-regulation of CD } 1 \mathrm{a} \text { in } \\
\text { iDCs. } \\
\text { Mechanism: inhibition of NF- } k \text { B signal } \\
\text { transduction pathway. }\end{array}$ \\
\hline Heat-shock proteins & HSP-27 & $\mathrm{D}$ & ED-1 & $\begin{array}{l}{[202} \\
203]\end{array}$ & Mechanism: IL-10 induction. \\
\hline Immuno-complexes & $\begin{array}{l}\text { Anti-OVA rabbit } \\
\text { IgG + OVA }\end{array}$ & $\mathrm{D}$ & ED-1 & {$[204]$} & $\begin{array}{l}\text { Mechanism: interaction with Fc } \gamma \text { RI and } \\
\text { Fc } \gamma \text { RII. }\end{array}$ \\
\hline \multirow[t]{2}{*}{ Ligand proteins } & $\begin{array}{l}\text { Peptide ligand of } \\
\text { melanocortin- } 4 \\
\text { receptor } \\
\text { (NDP-MSH) }\end{array}$ & $\mathrm{D}$ & ED-4 & {$[205]$} & $\begin{array}{l}\text { mDCs from treated precursors show } \\
\text { impaired ability to prime T-cells. }\end{array}$ \\
\hline & $\begin{array}{l}\text { sLAG-3 (CD223) } \\
\text { soluble MHC-II } \\
\text { ligand }\end{array}$ & $\mathrm{D}$ & $\begin{array}{l}\text { ED-1 } \\
\text { ED-3 }\end{array}$ & {$[206]$} & $\begin{array}{l}\text { CD1a down-regulation. Mechanism } \\
\text { (hypothesis): phosphorylation of PLC } 2 \text {, } \\
\text { p72syk, or AKT molecules. }\end{array}$ \\
\hline \multirow[t]{3}{*}{ Lipids } & Lipids & $\mathrm{D}$ & ED-1 & {$[207]$} & $\begin{array}{l}\text { High individual variability of CD1a } \\
\text { induction after G4. Lipoproteins (VLDL > } \\
\text { LDL > HDL) and PPAR } \gamma \text { activation reduce } \\
\text { the number of G4-induced CD } 1 \mathrm{a}^{+} \text {cells. }\end{array}$ \\
\hline & $\begin{array}{l}\text { Lysophosphatidic } \\
\text { acid (LPA) }\end{array}$ & $\mathrm{D}$ & ED-1 & {$[208]$} & $\begin{array}{l}\text { Mechanism: LPA is a potent natural ligand } \\
\text { for PPAR } \gamma \text {. }\end{array}$ \\
\hline & $\begin{array}{l}\text { Oxidized } \\
\text { Phospholipids }\end{array}$ & $\mathrm{D}$ & ED-1 & {$[209]$} & $\begin{array}{l}\text { Oxidized phospholipids (generated during } \\
\text { inflammation) down-regulate CD } 1 \mathrm{a} / \mathrm{b} / \mathrm{c} \text { and } \\
\text { block histone modifications required to } \\
\text { activate mDCs. }\end{array}$ \\
\hline \multirow{6}{*}{$\begin{array}{l}\text { Malignant cell } \\
\text { products }\end{array}$} & $\begin{array}{l}\text { Hepatoma cell } \\
\text { supernatant }\end{array}$ & $\mathrm{D}$ & ED-1 & {$[210]$} & $\begin{array}{l}\text { CD1a down-regulation by hepatoma but not } \\
\text { normal liver cell supernatants. Induction of } \\
\text { Treg Mechanism: possibly IL-10-dependent. }\end{array}$ \\
\hline & $\begin{array}{l}\text { Human renal cell } \\
\text { carcinoma lines }\end{array}$ & $\mathrm{D}$ & OED & {$[211]$} & $\begin{array}{l}\text { From CD } 34^{+} \text {progenitor cells: severe } \\
\text { inhibition of CD1a and APC function of } \\
\text { induced CDs. } \\
\text { Mechanism: possibly due, at least in part, to } \\
\text { IL- } 6 \text { and macrophage colony stimulating } \\
\text { factor. }\end{array}$ \\
\hline & $\begin{array}{l}\text { Leukemia cell } \\
\text { supernatant }\end{array}$ & $\mathrm{D}$ & $E D-1$ & {$[212]$} & $\begin{array}{l}\text { Supernatant of K562, HL- } 60 \text { and DAUDI on } \\
\text { CD1a expression. Mechanism: at least in } \\
\text { part, due to IL- } 1 \beta \text { secreted by MOs in } \\
\text { response to leukemic cell products. }\end{array}$ \\
\hline & $\begin{array}{l}\text { Melanoma cell } \\
\text { supernatant }\end{array}$ & $\mathrm{D}$ & $\begin{array}{l}\text { ED-1 } \\
\text { IvDC }\end{array}$ & {$[213]$} & $\begin{array}{l}\mathrm{CD} 1 \mathrm{a} / \mathrm{b} / \mathrm{c} \text {. Mechanism: IL-10 release } \\
\text { induction in vivo reduced CD1-positive cells } \\
\text { in metastatic melanoma. }\end{array}$ \\
\hline & & $\mathrm{D}$ & OED & {$[214]$} & $\begin{array}{l}\text { LC generated in vitro from cord blood } \\
\text { CD } 34^{+} \text {progenitors are CD1a-deficient } \\
\text { when cultured with melanoma cells in a } \\
\text { transwell design setting. }\end{array}$ \\
\hline & $\begin{array}{l}\text { Supernatant from } \\
\text { primary or } \\
\text { long-term } \\
\text { cultured tumor } \\
\text { cells }\end{array}$ & $\mathrm{D}$ & ED-1 & {$[215]$} & $\begin{array}{l}\text { Reduction of CD1a by supernatant of tumor } \\
\text { cell lines was much less active respect to } \\
\text { supernatants of primary tumors. Similar } \\
\text { results obtained with CD } 34^{+} \\
\text {progenitor-derived DCs. Mechanism: at least } \\
\text { in part mediated by PGE2 released by } \\
\text { primary tumor cells. }\end{array}$ \\
\hline
\end{tabular}


Table 4: Continued.

\begin{tabular}{|c|c|c|c|c|c|}
\hline $\begin{array}{l}\text { Type of biological } \\
\text { agents }\end{array}$ & Agent & $\mathrm{CD} 1^{\mathrm{a}}$ & $\mathrm{ED}^{\mathrm{b}}$ & Ref. ${ }^{c}$ & Observations \\
\hline Nucleotides & cAMP, cGMP & $\mathrm{D}$ & ED-1 & [216] & $\begin{array}{l}\text { cAMP increase was mimicked by the } \\
\text { adenylate cyclase activator forskolin or } \\
\text { cAMP analog } 8 \text { bromo-cAMP; cGMP } \\
\text { increase was mimicked by } 8 \text { bromo-cGMP; } \\
\text { increase of both was induced by PDE } \\
\text { inhibitor IBMX. Down regolation of CD1a } \\
\text { is followed by impairment of LPS-induced } \\
\text { mDC function. }\end{array}$ \\
\hline
\end{tabular}

$\begin{array}{lll}\text { Human serum } & \text { D }\end{array}$

Serum and serum components
$\operatorname{IgG}$

D

$\mathrm{D}$

ED-1

ED-4

$\beta 2$-microblobulin
$\mathrm{D}$

ED-1
ED-4
Human serum lipids: impairment of $\mathrm{CD} 1 \mathrm{a} / \mathrm{b} / \mathrm{c}$ transcription. Reduced induction of CD1c-restricted T-cell responses. Mechanism: PPAR $\gamma$ activation.

Human serum: Mechanism: PPAR $\gamma$ activation and IL-10 induction.

Autologous serum (iDCs from MOs or from CD $34^{+}$precursors).

Down-regulation of CD1a/b/c and upregulation of CD-1d transcripts. Mechanism: IgG-mediated activation of Fcy receptor Fc $\gamma$ RIIa (CD32a).

This study starts from the observation that intravenous immunoglobulin attenuates MS.

Down-regulation of CD1a and $\mathrm{mDC}$ function. Mechanism: inhibition of MAPK, ERK, MEK, and NF- $k$ B, and activation of STAT3.

Physical agents

UVAI
$(340-400 \mathrm{~nm})$

Ultraviolet light

D IvDC

UVB
D IvDC

D IvDC

Decrease of CDla ${ }^{+} \mathrm{LC}$ in a epidermis 3 days after ultraviolet exposure.

UV irradiation induces $\mathrm{CD} \mathrm{a}^{+} \mathrm{LC}$ down-regulation and IL-10 induction in vivo in skin. This is prevented in vivo by Zn-containing or octylmetoxy cinnamate sunscreen preparations.

$\mathrm{CD} \mathrm{a}^{+}$Langerhans cell loss after exposure of human epidermis and dermis to UVB, accompanied by infiltration with IL-10 producing macrophages.

Organ culture in vitro of human cornea (immunohistochemistry): low-dose UVB $\left(100 \mathrm{~mJ} / \mathrm{cm}^{2}\right)$ decreases HLA-DR and CD1a expression of organ-cultured human corneas and induces moderate corneal injuries, and might be useful for preventing allograft rejection.

\footnotetext{
${ }^{a}$ Evaluation of CD1a expression if not otherwise specified: U: upregulation; D: down-regulation.

${ }^{\mathrm{b}}$ Experimental design code (see Figure 2).

${ }^{\mathrm{c}}$ Reference number.
} 
TABLE 5: Influence exerted by infectious agents or microorganism products on group 1 CD1 antigen expression.

\begin{tabular}{|c|c|c|c|c|c|}
\hline $\begin{array}{l}\text { Infectious } \\
\text { Agent }\end{array}$ & Agent & $\mathrm{CD}^{\mathrm{a}}$ & $\mathrm{ED}^{\mathrm{b}}$ & Ref. $^{c}$ & Observations \\
\hline \multirow{4}{*}{ Bacteria } & $\begin{array}{l}\text { Helicobacter pilori } \\
\text { E. coli }\end{array}$ & $\mathrm{D}$ & ED-1 & {$[227]$} & $\begin{array}{l}\text { In vitro exposure to paraformaldehyde-fixed } \\
\text { bacteria. IL-10 independent. }\end{array}$ \\
\hline & $\begin{array}{l}\text { Helicobacter pilori } \\
\text { (in vivo) }\end{array}$ & $\mathrm{U}$ & IvDC & {$[228]$} & $\begin{array}{l}\text { In vivo detected by antral biopsies (lamina } \\
\text { propria): increased CD1a and CD1b in } \\
\text { infected children with respect to normal } \\
\text { subjects. Expression of local immune } \\
\text { responses. }\end{array}$ \\
\hline & $\begin{array}{l}\text { Propionibacterium } \\
\text { acnes }\end{array}$ & $\mathrm{U}$ & ED-2 & [229] & $\begin{array}{l}\text { Heat-killed bacteria added on day } 6 \text { to iDCs } \\
\text { of pts with acne vulgaris. }\end{array}$ \\
\hline & Various & $\mathrm{U}$ & OED & {$[230]$} & $\begin{array}{l}\text { Increased CD1a expression in in vitro } \\
\text { generation of mDCs from MS pts with } \\
\text { bacterial infections versus MS pts without } \\
\text { infections. }\end{array}$ \\
\hline Chlamydia & $\begin{array}{l}\text { Chlamydia } \\
\text { trachomatis }\end{array}$ & $\mathrm{U}$ & IvDC & {$[231]$} & $\begin{array}{l}\text { Myeloid DCs collected from cervical mucosa } \\
\text { of chlamydia-infected woman show myeloid } \\
\text { DCs with increased CD1a expression with } \\
\text { respect to that of healthy women. }\end{array}$ \\
\hline Mycoplasma & $\begin{array}{l}\text { Mycoplasma } \\
\text { present in cell } \\
\text { culture } \\
\text { supernatant }\end{array}$ & $\mathrm{D}$ & ED-1 & {$[232]$} & $\begin{array}{l}\text { If mycoplasma is removed, culture } \\
\text { supernatants are no more able to } \\
\text { down-regulate CD1a. }\end{array}$ \\
\hline \multirow{4}{*}{ Protozoa } & $\begin{array}{l}\text { Leishmania } \\
\text { donovani }\end{array}$ & $\mathrm{D}$ & ED-1 & {$[233]$} & $\begin{array}{l}\text { L. donovani infection in vitro impairs } \\
\text { induction of } \mathrm{CD} 1 \mathrm{a} / \mathrm{b} / \mathrm{c} \text { expression in terms } \\
\text { of gene transcript and protein. }\end{array}$ \\
\hline & $\begin{array}{l}\text { Leishmania } \\
\text { amazonensis }\end{array}$ & $\mathrm{D}$ & $\begin{array}{l}\text { ED-1 } \\
\text { ED-4 }\end{array}$ & {$[234]$} & $\begin{array}{l}\text { Leishmania or soluble Leishmania antigen } \\
\text { inhibited CDla expression, but did not } \\
\text { prevent further DC maturation toward } \\
\mathrm{CD}^{+} 3^{+} \text {mDCs. }\end{array}$ \\
\hline & $\begin{array}{l}\text { Leishmania } \\
\text { donovani and } \\
\text { Leishmania major }\end{array}$ & $\mathrm{D}$ & OED & {$[235]$} & $\begin{array}{l}\text { In vitro G4-induced iDCs were infected with } \\
\text { L. donovani or L. major on day } 7 \text { and tested } \\
\text { for CD } 1 \mathrm{a} / \mathrm{b} / \mathrm{c} / \mathrm{d} \text { expression } 8 \mathrm{~h} \text { later. } \\
\text { Down-regulation of mainly Group I CD } 1 \\
\text { molecules at the transcriptional (qRT-PCR) } \\
\text { and surface expression levels was detected. }\end{array}$ \\
\hline & $\begin{array}{l}\text { Toxoplasma } \\
\text { gondii }\end{array}$ & $\mathrm{NC}$ & OED & {$[236]$} & $\begin{array}{l}\text { In vitro infection of untreated MOs with } T \text {. } \\
\text { gondii does not induce CD1a. }\end{array}$ \\
\hline \multirow[t]{2}{*}{ Helminthes } & $\begin{array}{l}\text { Necator } \\
\text { Americanus }\end{array}$ & $\mathrm{D}$ & OED & [237] & $\begin{array}{l}\text { In vitro G4-induced CDla in mDCs is lower } \\
\text { when MOs were obtained from infected pts } \\
\text { versus normal donors. }\end{array}$ \\
\hline & $\begin{array}{l}\text { Echinococcus } \\
\text { granulosus }\end{array}$ & $\mathrm{D}$ & $\begin{array}{l}\text { ED-1 } \\
\text { ED-4 }\end{array}$ & $\begin{array}{l}{[238} \\
239]\end{array}$ & $\begin{array}{l}\text { Hydatid cyst components (AgB- and SHF) } \\
\text { down-regulate CD1a and further prevent } \\
\text { IL-12 production, increasing IL-10 release. }\end{array}$ \\
\hline \multirow[t]{2}{*}{$\begin{array}{l}\text { Viruses (for } \\
\text { HIV\& HTLV-I } \\
\text { see text) }\end{array}$} & $\begin{array}{l}\text { Human Herpes } \\
\text { Virus-8 (alive or } \\
\text { UV-inactivated) }\end{array}$ & $\mathrm{D}$ & ED-1 & {$[240]$} & $\begin{array}{l}\text { Reduced } \mathrm{mDC} \text { activity and sixfold reduction } \\
\text { in IL-12 ( } \mathrm{p} 70) \text { production with consequent } \\
\text { impairment of T-cell-mediated responses. }\end{array}$ \\
\hline & Cytomegalovirus & $\mathrm{D}$ & ED-1 & {$[241]$} & $\begin{array}{l}\text { CD1a assay at day 7, before adding LPS (to } \\
\text { evaluate iDC CD1a expression). } \\
\text { Down-regulation of CD1a occurs also with } \\
\text { UV-inactivated virus. Moreover, } \\
\text { HCMV-infected mDCs were unable to } \\
\text { induce a T-cell response, in line with the } \\
\text { immunodepressive effects of HCMV } \\
\text { infection. }\end{array}$ \\
\hline
\end{tabular}


Table 5: Continued.

\begin{tabular}{|c|c|c|c|c|c|}
\hline $\begin{array}{l}\text { Infectious } \\
\text { Agent }\end{array}$ & Agent & $\mathrm{CD}^{\mathrm{a}}$ & $\mathrm{ED}^{\mathrm{b}}$ & Ref. $^{c}$ & Observations \\
\hline
\end{tabular}

Micro-

Organism

products

\begin{tabular}{|c|c|c|c|c|c|}
\hline $\begin{array}{l}\text { Bordetella } \\
\text { pertussis }\end{array}$ & Pertussis toxin & $\mathrm{D}$ & ED-1 & {$[242]$} & $\begin{array}{l}\text { Selective suppression of CD1a (mRNA and } \\
\text { protein) but not of CD1b and CD1c. } \\
\text { LPS-induced mDCs are functionally } \\
\text { normal. }\end{array}$ \\
\hline $\begin{array}{l}\text { Candida } \\
\text { albicans }\end{array}$ & Supernatant & $\mathrm{D}$ & ED-1 & {$[243]$} & $\begin{array}{l}\text { C. albicans supernatants contain a } \\
\text { glycoprotein termed "Secretory IL- } 12 \\
\text { Inhibitory Factor", able to down-regulate } \\
\text { CD la expression and IL-12 production by } \\
\text { iDCs and DCs. }\end{array}$ \\
\hline Dengue & $\begin{array}{l}\text { Dengue-2 (live } \\
\text { attenuated } \\
\text { vaccines) }\end{array}$ & $\mathrm{U}$ & ED-2 & {$[244]$} & $\begin{array}{l}\text { DC maturation step } 2 \text { was attained with live } \\
\text { attenuate vaccine LAV } 2 \text { or DEN2 without } \\
\text { adding LPS. Heat-inactivated virus was used } \\
\text { as a negative control for virus infection. } \\
\text { CD1a assay was performed after incubation } \\
\text { at } 32^{\circ} \mathrm{C} \text { for } 48 \mathrm{~h} \text {. }\end{array}$ \\
\hline \multirow[t]{2}{*}{ Malaria } & $\begin{array}{l}\text { Hemozoin } \\
\text { (malaria } \\
\text { pigment) }\end{array}$ & $\mathrm{D}$ & $\begin{array}{l}\text { ED-1 } \\
\text { ED-4 }\end{array}$ & {$[245]$} & $\begin{array}{l}\text { Mechanism: increased PPAR } \gamma \text { expression } \\
\text { (qRT-PCR) following hemozoin-induced } \\
\text { activation in MOs. }\end{array}$ \\
\hline & $\begin{array}{l}\text { Atypical } \\
\text { Membrane } \\
\text { Antigen-1 } \\
\text { (AMA-1) }\end{array}$ & $\mathrm{U}$ & $\mathrm{ED}-4$ & {$[246]$} & $\begin{array}{l}\mathrm{mDC} \text { of } P \text {. vivax infected pts show lower } \\
\text { CD1a expression than that of mDCs } \\
\text { developed in vitro from MOs of noninfected } \\
\text { controls. In vitro exposure to AMA-1 } \\
\text { increases CDla levels in mDCs developed in } \\
\text { vitro from MOs of infected donors. }\end{array}$ \\
\hline Mycotoxins & $\mathrm{T}-2$ toxin & $\mathrm{D}$ & ED-1 & {$[247]$} & Strong inhibition. \\
\hline
\end{tabular}

$\begin{array}{lll}\begin{array}{l}\text { Staphylococcus } \\ \text { aureus }\end{array} & \begin{array}{l}\text { Staphylococcus } \\ \text { superantigen }\end{array} & \mathrm{U}\end{array}$

$\mathrm{CDla}^{+}$cell number in the epidermis was significantly higher in the lesional skin with respect to that in non-lesional skin from atopic dermatitis pts or to that in the skin from normal donors.
LPS (from Salmonella) was added to MOs+G4 culture on day 0 instead of on day 5-9, as usually used for inducing iDC maturation to mDCs. Mechanism: in part by induction of IL-10, and mostly by MAPKp38 activation followed by ERK and $\mathrm{NF}-k \mathrm{~B}$ inactivation.

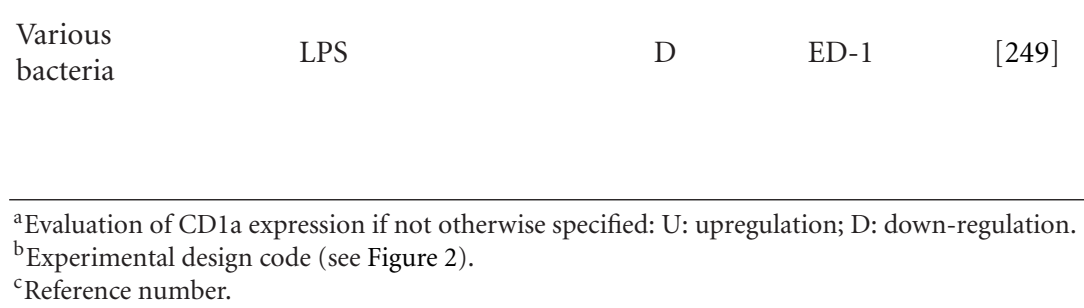

planning new types of antimycobacterial vaccines. It is reasonable to predict that properly designed siRNA(s) could be combined in a near future, with BCG or BCG-like vaccines in order to obtain gene silencing vaccines able to inactivate the intracellular signals responsible of Group I CD1 protein suppression.

\section{Abbreviations}

Ac2SGL: Acylated sulfoglycolipid

APC: Antigen-presenting cells

ASA: Acetylsalicylic acid

ATF-2: Activating transcription factor 


\begin{tabular}{|c|c|}
\hline ATRA: & All trans-retinoic acid \\
\hline AZT: & Zidovudine \\
\hline BCG: & Bacillus Calmette-Guerin \\
\hline BDP: & Beclomethasone dipropionate \\
\hline CRE: & cAMP response element \\
\hline CREB-1: & CRE-binding protein \\
\hline DC: & Dendritic cells \\
\hline DEX: & Dexamethasone \\
\hline ERK: & Extracellular signal-regulated kinases \\
\hline G4: & GM-CSF + IL-4 \\
\hline GA: & Glatiramer acetate \\
\hline GM-CSF: & $\begin{array}{l}\text { Granulocyte-macrophage colony } \\
\text { stimulating factor }\end{array}$ \\
\hline GST: & Gold sodium thiomalate \\
\hline HDAC: & Histone deacetylases \\
\hline iDC: & Immature dendritic cells \\
\hline IFN: & Interferon \\
\hline IL: & Interleukin \\
\hline LC: & Langerhans cells \\
\hline LPS: & Lipopolysaccharides \\
\hline MAPK: & Mitogen-activated protein kinase \\
\hline mDC: & Mature dendritic cells \\
\hline MDR: & Multidrug resistance \\
\hline MIN: & Minocycline \\
\hline MM: & Multiple myeloma \\
\hline MMF: & Monomethyl-fumarate \\
\hline MOs: & Monocytes \\
\hline MRP1: & Multidrug resistance protein 1 \\
\hline MS: & Multiple sclerosis \\
\hline MTP: & $\begin{array}{l}\text { Microsomal triglyceride transfer } \\
\text { protein }\end{array}$ \\
\hline NFA: & Niflumic acid \\
\hline NSAID: & $\begin{array}{l}\text { Nonsteroidal anti-inflammatory } \\
\text { drugs }\end{array}$ \\
\hline PBMN: & Peripheral blood mononuclear cells \\
\hline PPAR: & $\begin{array}{l}\text { Peroxisome proliferator-activated } \\
\text { receptor }\end{array}$ \\
\hline pts: & Patients \\
\hline RA: & Rheumatoid arthritis \\
\hline TCR: & T-cell receptor \\
\hline TLR: & Toll-like receptors \\
\hline TNF: & Tumor necrosis factor. \\
\hline
\end{tabular}

\section{Acknowledgment}

This work was supported by a grant for tuberculosis investigations provided by the "Provincia di Roma", Rome, Italy.

\section{References}

[1] P. G. Lin and J. L. Flynn, "Understanding latent tuberculosis: a moving target," Journal of Immunology, vol. 185, no. 1, pp. $15-22,2010$.

[2] J. L. Flynn, J. Chan, K. J. Triebold, D. K. Dalton, T. A. Stewart, and B. R. Bloom, "An essential role for interferon $\gamma$ in resistance to Mycobacterium tuberculosis infection," Journal of Experimental Medicine, vol. 178, no. 6, pp. 2249-2254, 1993.

[3] S. Porcelli, M. B. Brenner, J. L. Greenstein, S. P. Balk, C. Terhorst, and P. A. Bleicher, "Recognition of cluster of differentiation 1 antigens by human $\mathrm{CD} 4^{-} \mathrm{CD} 8^{-}$cytolytic $\mathrm{T}$ lymphocytes," Nature, vol. 341, no. 6241, pp. 447-450, 1989.

[4] S. Porcelli, C. T. Morita, and M. B. Brenner, "CD1b restricts the response of human $\mathrm{CD}^{-} \mathrm{CD}^{-} \mathrm{T}$ lymphocytes to a microbial antigen," Nature, vol. 360, no. 6404, pp. 593-597, 1992.

[5] E. M. Beckman, S. A. Porcelli, C. T. Morita, S. M. Behar, S. T. Furlong, and M. B. Brenner, "Recognition of lipid antigen by CD1-restricted $\alpha \beta^{+}$T cells," Nature, vol. 372, no. 6507, pp. 691-694, 1994.

[6] N. R. Cohen, S. Garg, and M. B. Brenner, "Chapter 1 antigen presentation by CD1. Lipids, T cells, and NKT cells in microbial immunity," Advances in Immunology, vol. 102, pp. 1-94, 2009.

[7] M. Taniguchi and T. Nakayama, "Recognition and function of V $\alpha 14$ NKT cells," Seminars in Immunology, vol. 12, no. 6, pp. 543-550, 2000.

[8] D. Betel, A. Koppal, P. Agius, C. Sander, and C. Leslie, "Comprehensive modeling of microRNA targets predicts functional non-conserved and non-canonical sites," Genome Biology, vol. 11, article R90, 2010.

[9] W. Kasinrerk, T. Baumruker, O. Majdic, W. Knapp, and H. Stockinger, "CD1 molecule expression on human monocytes induced by granulocyte- macrophage colony-stimulating factor," Journal of Immunology, vol. 150, no. 2, pp. 579-584, 1993.

[10] S. A. Porcelli and R. L. Modlin, "The CD1 system: antigenpresenting molecules for $\mathrm{T}$ cell recognition of lipids and glycolipids," Annual Review of Immunology, vol. 17, pp. 297329, 1999.

[11] U. E. Schaible, K. Hagens, K. Fischer, H. L. Collins, and S. H. E. Kaufmann, "Intersection of group I CD1 molecules and mycobacteria in different intracellular compartments of dendritic cells," Journal of Immunology, vol. 164, no. 9, pp. 4843-4852, 2000.

[12] M. Salio, J. D. Silk, and V. Cerundolo, "Recent advances in processing and presentation of CD1 bound lipid antigens," Current Opinion in Immunology, vol. 22, no. 1, pp. 81-88, 2010.

[13] E. M. Beckman, S. A. Porcelli, C. T. Morita, S. M. Behar, S. T. Furlong, and M. B. Brenner, "Recognition of lipid antigen by CD1-restricted $\alpha \beta$ T cells," Nature, vol. 372, no. 6507, pp. 691-694, 1994.

[14] S. A. Porcelli, "The CD1 family: a third lineage of antigenpresenting molecules," Advances in Immunology, vol. 59, pp. 1-98, 1995.

[15] S. Stenger, R. J. Mazzaccaro, K. Uyemura et al., "Differential effects of cytolytic T cell subsets on intracellular infection," Science, vol. 276, no. 5319, pp. 1684-1687, 1997.

[16] P. A. Sieling, M. T. Ochoa, D. Jullien et al., "Evidence for human $\mathrm{CD}^{-} \mathrm{T}$ cells in the $\mathrm{CD} 1$-restricted repertoire: derivation of mycobacteria-reactive $\mathrm{T}$ cells from leprosy lesions," Journal of Immunology, vol. 164, no. 9, pp. 47904796, 2000.

[17] Y. Cui, L. Kang, L. Cui, and W. He, "Human $\gamma \delta$ T cell Recognition of lipid A is predominately presented by CD1b or CD1c on dendritic cells," Biology Direct, vol. 4, article 47, 2009.

[18] S. Thoma-Uszynski, S. Stenger, and R. L. Modlin, "CTLmediated killing of intracellular Mycobacterium tuberculosis is independent of target cell nuclear apoptosis," Journal of Immunology, vol. 165, no. 10, pp. 5773-5779, 2000. 
[19] M. Brigl and M. B. Brenner, "CD1: antigen presentation and T cell function," Annual Review of Immunology, vol. 22, pp. 817-890, 2004.

[20] M. S. Vincent, J. E. Gumperz, and M. B. Brenner, "Understanding the function of CD1-restricted T cells," Nature Immunology, vol. 4, no. 6, pp. 517-523, 2003.

[21] P. Méndez-Samperio, "Role of interleukin-12 family cytokines in the cellular response to mycobacterial disease," International Journal of Infectious Diseases, vol. 14, no. 5, pp. e366-e371, 2010.

[22] G. De Libero and L. Mori, "Structure and biology of self lipid antigens," Current Topics in Microbiology and Immunology, vol. 314, pp. 51-72, 2007.

[23] M. M. Blewett, "Lipid autoreactivity in multiple sclerosis," Medical Hypotheses, vol. 74, no. 3, pp. 433-442, 2010.

[24] C. C. Dascher, K. Hiromatsu, X. Xiong et al., "Immunization with a mycobacterial lipid vaccine improves pulmonary pathology in the guinea pig model of tuberculosis," International Immunology, vol. 15, no. 8, pp. 915-925, 2003.

[25] K. Hiromatsu, C. C. Dascher, K. P. LeClair et al., "Induction of CD1-restricted immune responses in guinea pigs by immunization with mycobacterial lipid antigens," Journal of Immunology, vol. 169, no. 1, pp. 330-339, 2002.

[26] K. Felio, H. Nguyen, C. C. Dascher et al., "CD1-restricted adaptive immune responses to Mycobacteria in human group 1 CD1 transgenic mice," Journal of Experimental Medicine, vol. 206, no. 11, pp. 2497-2509, 2009.

[27] A. Colmone, S. Li, and C. R. Wang, "Activating transcription factor/cAMP response element binding protein family member regulated transcription of CD1A," Journal of Immunology, vol. 177, no. 10, pp. 7024-7032, 2006.

[28] K. Niwano, M. Arai, N. Koitabashi et al., "Competitive binding of CREB and ATF2 to CAMP/ATF responsive element regulates eNOS gene expression in endothelial cells," Arteriosclerosis, Thrombosis, and Vascular Biology, vol. 26, no. 5, pp. 1036-1042, 2006.

[29] V. Havelange and R. Garzon, "Micrornas: emerging key regulators of hematopoiesis," American Journal of Hematology, vol. 85, no. 12, pp. 935-942, 2010.

[30] B. S. Cobb, A. Hertweck, J. Smith et al., "A role for Dicer in immune regulation," Journal of Experimental Medicine, vol. 203, no. 11, pp. 2519-2527, 2006.

[31] M. A. Lindsay, "microRNAs and the immune response," Trends in Immunology, vol. 29, no. 7, pp. 343-351, 2008.

[32] A. Recchiuti, S. Krishnamoorthy, G. Fredman et al., "MicroRNAs in resolution of acute inflammation: identification of novel resolvin D1-miRNA circuits," FASEB Journal, vol. 25, no. 2, pp. 544-560, 2011.

[33] H. Kuipers, F. M. Schnorfeil, H.-J. Fehling, H. Bartels, and T. Brocker, "Dicer-dependent microRNAs control maturation, function, and maintenance of Langerhans cells in vivo," Journal of Immunology, vol. 185, no. 1, pp. 400-409, 2010.

[34] V. I. D. Ros and G. D. D. Hurst, "Lateral gene transfer between prokaryotes and multicellular eukaryotes: ongoing and significant?" BMC Biology, vol. 7, article 20, 2009.

[35] J. M. DiChiara, L. M. Contreras-Martinez, J. Livny, D. Smith, K. A. McDonough, and M. Belfort, "Multiple small RNAs identified in Mycobacterium bovis BCG are also expressed in Mycobacterium tuberculosis and Mycobacterium smegmatis," Nucleic Acids Research, vol. 38, no. 12, pp. 4067-4078, 2010.

[36] T. Akama, K. Suzuki, K. Tanigawa et al., "Whole-genome tiling array analysis of Mycobacterium leprae RNA reveals high expression of pseudogenes and noncoding regions," Journal of Bacteriology, vol. 191, no. 10, pp. 3321-3327, 2009.
[37] Y. Watanabe, E. Watari, I. Matsunaga et al., "BCG vaccine elicits both T-cell mediated and humoral immune responses directed against mycobacterial lipid components," Vaccine, vol. 24, no. 29-30, pp. 5700-5707, 2006.

[38] J. Liu, V. Tran, A. S. Leung, D. C. Alexander, and B. Zhu, "BCG vaccines: their mechanisms of attenuation and impact on safety and protective efficacy," Human Vaccines, vol. 5, no. 2, pp. 70-78, 2009.

[39] L. F. Barker, M. J. Brennan, P. K. Rosenstein, and J. C. Sadoff, "Tuberculosis vaccine research: the impact of immunology," Current Opinion in Immunology, vol. 21, no. 3, pp. 331-338, 2009.

[40] L. J. Alderwick, H. L. Birch, A. K. Mishra, L. Eggeling, and G. S. Besra, "Structure, function and biosynthesis of the Mycobacterium tuberculosis cell wall: arabinogalactan and lipoarabinomannan assembly with a view to discovering new drug targets," Biochemical Society Transactions, vol. 35, no. 5, pp. 1325-1328, 2007.

[41] D. B. Moody, D. C. Young, T. Y. Cheng et al., "T cell activation by lipopeptide antigens," Science, vol. 303, no. 5657, pp. 527$531,2004$.

[42] D. B. Moody, T. Ulrichs, W. Mühlecker et al., "CD1cmediated T-cell recognition of isoprenoid glycolipids in Mycobacterium tuberculosis infection," Nature, vol. 404, no. 6780, pp. 884-888, 2000.

[43] M. Gilleron, S. Stenger, Z. Mazorra et al., "Diacylated sulfoglycolipids are novel mycobacterial antigens stimulating CD1-restricted T Cells during Infection with Mycobacterium tuberculosis," Journal of Experimental Medicine, vol. 199, no. 5, pp. 649-659, 2004.

[44] G. De Libero and L. Mori, "Recognition of lipid antigens by T cells," Nature Reviews Immunology, vol. 5, no. 6, pp. 485-496, 2005.

[45] J. Guiard, A. Collmann, L. F. Garcia-Alles et al., "Fatty acyl structures of Mycobacterium tuberculosis sulfoglycolipid govern T cell response," Journal of Immunology, vol. 182, no. 11, pp. 7030-7037, 2009.

[46] A. Kasmar, I. Van Rhijn, and D. B. Moody, "The evolved functions of CD1 during infection," Current Opinion in Immunology, vol. 21, no. 4, pp. 397-403, 2009.

[47] P. A. Sieling, D. Jullien, M. Dahlem et al., "CD1 expression by dendritic cells in human leprosy lesions: correlation with effective host immunity," Journal of Immunology, vol. 162, no. 3, pp. 1851-1858, 1999.

[48] L. F. Barker, M. J. Brennan, P. K. Rosenstein, and J. C. Sadoff, "Tuberculosis vaccine research: the impact of immunology," Current Opinion in Immunology, vol. 21, no. 3, pp. 331-338, 2009.

[49] P. A. Sieling, J. B. Torrelles, S. Stenger et al., "The human CD1-restricted T cell repertoire is limited to cross-reactive antigens: implications for host responses against immunologically related pathogens," Journal of Immunology, vol. 174, no. 5, pp. 2637-2644, 2005.

[50] T. Ulrichs, D. B. Moody, E. Grant, S. H. E. Kaufmann, and S. A. Porcelli, "T-cell responses to CD1-presented lipid antigens in humans with Mycobacterium tuberculosis infection," Infection and Immunity, vol. 71, no. 6, pp. 30763087, 2003.

[51] X. Chen, B. Zhou, M. Li et al., "CD $4^{+} \mathrm{CD} 25^{+} \mathrm{FoxP} 3^{+}$regulatory T cells suppress Mycobacterium tuberculosis immunity in patients with active disease," Clinical Immunology, vol. 123, no. 1, pp. 50-59, 2007.

[52] M. S. Vincent, X. Xiong, E. P. Grant, W. Peng, and M. B. Brenner, "CDla-, b-, and c-restricted TCRs recognize both 
self and foreign antigens," Journal of Immunology, vol. 175, no. 10, pp. 6344-6351, 2005.

[53] T. K. A. Nguyen, A. P. Koets, W. J. Santema, W. van Eden, V. P. M. G. Rutten, and I. Van Rhijn, "The mycobacterial glycolipid glucose monomycolate induces a memory $\mathrm{T}$ cell response comparable to a model protein antigen and no B cell response upon experimental vaccination of cattle," Vaccine, vol. 27, no. 35, pp. 4818-4825, 2009.

[54] S. H. E. Kaufmann, "Protection against tuberculosis: cytokines, T cells, and macrophages," Annals of the Rheumatic Diseases, vol. 61, no. 2, pp. ii54-ii58, 2002.

[55] J. Lee and H. Kornfeld, "Interferon- $\gamma$ regulates the death of M. tuberculosis-infected macrophages," Journal of Cell Death , vol. 3, pp. 1-11, 2010.

[56] A. Baena and S. A. Porcelli, "Evasion and subversion of antigen presentation by Mycobacterium tuberculosis," Tissue Antigens, vol. 74, no. 3, pp. 189-204, 2009.

[57] M. González-Juarrero and M. P. O’Sullivan, “Optimization of inhaled therapies for tuberculosis: the role of macrophages and dendritic cells," Tuberculosis, vol. 91, no. 1, pp. 86-92, 2011.

[58] L. S. Meena and T. Rajni, "Survival mechanisms of pathogenic Mycobacterium tuberculosis H37 Rv," FEBS Journal, vol. 277, no. 11, pp. 2416-2427, 2010.

[59] M. L. Lang and A. Glatman-Freedman, "Do CD1-restricted $\mathrm{T}$ cells contribute to antibody-mediated immunity against Mycobacterium tuberculosis?" Infection and Immunity, vol. 74, no. 2, pp. 803-809, 2006.

[60] R. Jayachandran, V. Sundaramurthy, B. Combaluzier et al., "Survival of Mycobacteria in macrophages is mediated by coronin 1-dependent activation of calcineurin," Cell, vol. 130, no. 1, pp. 37-50, 2007.

[61] F. Winau, S. H. E. Kaufmann, and U. E. Schaible, "Apoptosis paves the detour path for CD8T cell activation against intracellular bacteria," Cellular Microbiology, vol. 6, no. 7, pp. 599-607, 2004.

[62] L. Danelishvili, Y. Yamazaki, J. Selker, and L. E. Bermudez, "Secreted Mycobacterium tuberculosis Rv3654c and Rv3655c proteins participate in the suppression of macrophage apoptosis," PLoS ONE, vol. 5, no. 5, Article ID e10474, 2010.

[63] S. Stenger, K. R. Niazi, and R. L. Modlin, "Down-regulation of CD1 on antigen-presenting cells by infection with Mycobacterium tuberculosis," Journal of Immunology, vol. 161, no. 7, pp. 3582-3588, 1998.

[64] S. P. Prete, G. Girolomoni, A. Giuliani et al., "Limited introduction of CD1b expression by BCG in human adherent mononuclear cells is mediated by GM-CSF," Journal of Chemotherapy, vol. 12, supplement 6, p. 146, 2000.

[65] C. Roura-Mir, L. Wang, T. Y. Cheng et al., "Mycobacterium tuberculosis regulates $\mathrm{CD} 1$ antigen presentation pathways through TLR-2," Journal of Immunology, vol. 175, no. 3, pp. 1758-1766, 2005.

[66] P. A. Videira, F. M. Calais, M. Correia et al., "Efficacy of Bacille Calmette-Guérin immunotherapy predicted by expression of antigen-presenting molecules and chemokines," Urology, vol. 74, no. 4, pp. 944-950, 2009.

[67] A. Miranda, T. P. Amadeu, G. Schueler et al., "Increased Langerhans cell accumulation after mycobacterial stimuli," Histopathology, vol. 51, no. 5, pp. 649-656, 2007.

[68] P. Rajashree, G. Krishnan, and S. D. Das, "Impaired phenotype and function of monocyte derived dendritic cells in pulmonary tuberculosis," Tuberculosis, vol. 89, no. 1, pp. 7783, 2009.
[69] S. P. Prete, A. Giuliani, E. Iona et al., "Bacillus CalmetteGuerin down-regulates CD1b induction by granulocytemacrophage colony stimulating factor in human peripheral blood monocytes," Journal of Chemotherapy, vol. 13, no. 1, pp. 52-58, 2001.

[70] A. Giuliani, S. P. Prete, G. Graziani et al., "Influence of Mycobacterium bovis bacillus Calmette Guérin on in vitro induction of CD1 molecules in human adherent mononuclear cells," Infection and Immunity, vol. 69, no. 12, pp. 74617470, 2001.

[71] S. Mariotti, R. Teloni, E. Iona et al., "Mycobacterium tuberculosis subverts the differentiation of human monocytes into dendritic cells," European Journal of Immunology, vol. 32, no. 11, pp. 3050-3058, 2002.

[72] M. C. Gagliardi, R. Teloni, S. Mariotti et al., "Bacillus Calmette-Guérin shares with virulent Mycobacterium tuberculosis the capacity to subvert monocyte differentiation into dendritic cell: Implication for its efficacy as a vaccine preventing tuberculosis," Vaccine, vol. 22, no. 29-30, pp. 3848-3857, 2004.

[73] A. Martino, A. Sacchi, E. Volpe et al., "Non-pathogenic Mycobacterium smegmatis induces the differentiation of human monocytes directly into fully mature dendritic cells," Journal of Clinical Immunology, vol. 25, no. 4, pp. 365-375, 2005.

[74] S. P. Prete, A. Giuliani, S. D’Atri et al., "BCG-infected adherent mononuclear cells release cytokines that regulate group 1 CD1 molecule expression," International Immunopharmacology, vol. 7, no. 3, pp. 321-332, 2007.

[75] M. C. Gagliardi, R. Teloni, F. Giannoni et al., "Mycobacteria exploit p38 signaling to affect CD1 expression and lipid antigen presentation by human dendritic cells," Infection and Immunity, vol. 77, no. 11, pp. 4947-4952, 2009.

[76] M. E. Remoli, E. Giacomini, E. Petruccioli et al., "Bystander inhibition of dendritic celldifferentiation by Mycobacterium tuberculosis-induced IL-10," Immunology and Cell Biology. 31 August 2010.

[77] S. B. Jung, C. H. Song, C. S. Yang et al., "Role of the phosphatidylinositol 3-kinase and mitogen-activated protein kinase pathways in the secretion of tumor necrosis factor$\alpha$ and interleukin-10 by the PPD antigen of Mycobacterium tuberculosis," Journal of Clinical Immunology, vol. 25, no. 5, pp. 482-490, 2005.

[78] N. Reiling, A. Blumenthal, H. D. Flad, M. Ernst, and S. Ehlers, "Mycobacteria-induced TNF- $\alpha$ and IL-10 formation by human macrophages is differentially regulated at the level of mitogen-activated protein kinase activity," Journal of Immunology, vol. 167, no. 6, pp. 3339-3345, 2001.

[79] C. H. Song, J. S. Lee, S. H. Lee et al., "Role of mitogenactivated protein kinase pathways in the production of tumor necrosis factor- $\alpha$, interleukin-10, and monocyte chemotactic protein-1 by Mycobacterium tuberculosis H37Rv-infected human monocytes," Journal of Clinical Immunology, vol. 23, no. 3, pp. 194-201, 2003.

[80] P. Méndez-Samperio, A. Trejo, and A. Pérez, "Mycobacterium bovis Bacillus Calmette-Guérin (BCG) stimulates IL10 production via the PI3K/Akt and p38 MAPK pathways in human lung epithelial cells," Cellular Immunology, vol. 251, no. 1, pp. 37-42, 2008.

[81] C. D. Souza, O. A. Evanson, and D. J. Weiss, "Mitogen activated protein kinase pathway is an important component of the anti-inflammatory response in Mycobacterium avium subsp. paratuberculosis-infected bovine monocytes," Microbial Pathogenesis, vol. 41, no. 2-3, pp. 59-66, 2006. 
[82] B. K. W. Cheung, D. C. W. Lee, J. C. B. Li, YU. L. Lau, and A. S. Y. Lau, "A role for double-stranded RNA-activated protein kinase PKR in Mycobacterium-induced cytokine expression," Journal of Immunology, vol. 175, no. 11, pp. 7218-7225, 2005.

[83] M. M. P. Chan, B. K. W. Cheung, J. C. B. Li, L. L. Y. Chan, and A. S. Y. Lau, "A role for glycogen synthase kinase-3 in antagonizing mycobacterial immune evasion by negatively regulating IL-10 induction," Journal of Leukocyte Biology, vol. 86, no. 2, pp. 283-291, 2009.

[84] S. Nair, P. A. Ramaswamy, S. Ghosh et al., "The PPE18 of Mycobacterium tuberculosis interacts with TLR2 and activates IL-10 induction in macrophage," Journal of Immunology, vol. 183, no. 10, pp. 6269-6281, 2009.

[85] L. Balboa, M. M. Romero, N. Yokobori et al., "Mycobacterium tuberculosis impairs dendritic cell response by altering CD1b, DC-SIGN and MR profile," Immunology and Cell Biology, vol. 88, no. 7, pp. 716-726, 2010.

[86] J. L. Strominger, "An alternative path for antigen presentation: group 1 CD1 proteins," Journal of Immunology, vol. 184, no. 7, pp. 3303-3305, 2010.

[87] A. Shamshiev, A. Donda, T. I. Prigozy et al., "The $\alpha \beta$ T cell response to self-glycolipids shows a novel mechanism of CD1b loading and a requirement for complex oligosaccharides," Immunity, vol. 13, no. 2, pp. 255-264, 2000.

[88] V. Manolova, M. Kistowska, S. Paoletti et al., "Functional CD1a is stabilized by exogenous lipids," European Journal of Immunology, vol. 36, no. 5, pp. 1083-1092, 2006.

[89] M. Cernadas, M. Cavallari, G. Watts, L. Mori, G. De Libero, and M. B. Brenner, "Early recycling compartment trafficking of CDla is essential for its intersection and presentation of lipid antigens," Journal of Immunology, vol. 184, no. 3, pp. 1235-1241, 2010.

[90] M. Sugita, N. van der Wel, R. A. Rogers, P. J. Peters, and M. B. Brenner, "CD1c molecules broadly survey the endocytic system," Proceedings of the National Academy of Sciences of the United States of America, vol. 97, no. 15, pp. 8445-8450, 2000.

[91] D. Zhou, C. Cantu III, Y. Sagiv et al., "Editing of CD1dbound lipid antigens by endosomal lipid transfer proteins," Science, vol. 303, no. 5657, pp. 523-527, 2004.

[92] P. van den Elzen, S. Garg, L. León et al., "Apolipoproteinmediated pathways of lipid antigen presentation," Nature, vol. 437, no. 7060, pp. 906-910, 2005.

[93] H. de la Salle, S. Mariotti, C. Angenieux et al., "Immunology: assistance of microbial glycolipid antigen processing by CD1e," Science, vol. 310, no. 5752, pp. 1321-1324, 2005.

[94] S. Tourne, B. Maitre, A. Collmann et al., "Cutting edge: a naturally occurring mutation in CD1e impairs lipid antigen presentation," Journal of Immunology, vol. 180, no. 6, pp. 3642-3646, 2008.

[95] M. Relloso, T. Y. Cheng, J. S. Im et al., "pH-Dependent Interdomain Tethers of CD1b Regulate Its Antigen Capture," Immunity, vol. 28, no. 6, pp. 774-786, 2008.

[96] E. Shinya, A. Owaki, M. Shimizu et al., "Endogenously expressed HIV-1 nef down-regulates antigen-presenting molecules, not only class I MHC but also CD1a, in immature dendritic cells," Virology, vol. 326, no. 1, pp. 79-89, 2004.

[97] M. G. Quaranta, E. Tritarelli, L. Giordani, and M. Viora, "HIV-1 Nef induces dendritic cell differentiation: a possible mechanism of uninfected $\mathrm{CD} 4^{+} \mathrm{T}$ cell activation," Experimental Cell Research, vol. 275, no. 2, pp. 243-254, 2002.

[98] R. D. Wiley and S. Gummuluru, "Immature dendritic cell-derived exosomes can mediate HIV-1 trans infection," Proceedings of the National Academy of Sciences of the United States of America, vol. 103, no. 3, pp. 738-743, 2006.
[99] A. Sacchi, G. Cappelli, C. Cairo et al., "Differentiation of monocytes into CD1a- dendritic cells correlates with disease progression in HIV-infected patients," Journal of Acquired Immune Deficiency Syndromes, vol. 46, no. 5, pp. 519-528, 2007.

[100] M. Makino, S. I. Wakamatsu, S. Shimokubo, N. Arima, and M. Baba, "Production of functionally deficient dendritic cells from HTLV-I-infected monocytes: implications for the dendritic cell defect in adult T cell leukemia," Virology, vol. 274, no. 1, pp. 140-148, 2000.

[101] B. Ensoli, L. Buonaguro, G. Barillari et al., "Release, uptake, and effects of extracellular human immunodeficiency virus type 1 Tat protein on cell growth and viral transactivation," Journal of Virology, vol. 67, no. 1, pp. 277-287, 1993.

[102] K. Gee, J. B. Angel, S. Mishra, M. A. Blahoianu, and A. Kumar, "IL-10 regulation by HIV-tat in primary human monocytic cells: involvement of calmodulin/calmodulindependent protein kinase-activated p38 MAPIC and Sp-1 and CREB-1 transcription factors," Journal of Immunology, vol. 178, no. 2, pp. 798-807, 2007.

[103] T. De Smedt, M. Van Mechelen, G. De Becker, J. Urbain, O. Leo, and M. Moser, "Effect of interleukin-10 on dendritic cell maturation and function," European Journal of Immunology, vol. 27, no. 5, pp. 1229-1235, 1997.

[104] C. Buelens, V. Verhasselt, D. De Groote, K. Thielemans, M. Goldman, and F. Willems, "Interleukin-10 prevents the generation of dendritic cells from human peripheral blood mononuclear cells cultured with interleukin-4 and granulocyte/macrophage-colony-stimulating factor," European Journal of Immunology, vol. 27, no. 3, pp. 756-762, 1997.

[105] P. Allavena, L. Piemonti, D. Longoni et al., "IL-10 prevents the differentiation of monocytes to dendritic cells but promotes their maturation to macrophages," European Journal of Immunology, vol. 28, no. 1, pp. 359-369, 1998.

[106] G. Gerlini, A. Tun-Kyi, C. Dudli, G. Burg, N. Pimpinelli, and F. O. Nestle, "Metastatic melanoma secreted IL-10 downregulates $\mathrm{CD} 1$ molecules on dendritic cells in metastatic tumor lesions," American Journal of Pathology, vol. 165, no. 6, pp. 1853-1863, 2004.

[107] K. A. Nahmod, M. E. Vermeulen, S. Raiden et al., "Control of dendritic cell differentiation by angiotensin II," The FASEB Journal, vol. 17, no. 3, pp. 491-493, 2003.

[108] A. Tanaka, K. Minoguchi, K. T. R. Samson et al., "Inhibitory effects of suplatast tosilate on the differentiation and function of monocyte-derived dendritic cells from patients with asthma," Clinical and Experimental Allergy, vol. 37, no. 7, pp. 1083-1089, 2007.

[109] E. M. Knijff, C. Ruwhof, H. J. De Wit et al., "Monocytederived dendritic cells in bipolar disorder," Biological Psychiatry, vol. 59, no. 4, pp. 317-326, 2006.

[110] K.-J. Liu, Y.-L. Lee, Y.-Y. Yang et al., "Modulation of the development of human monocyte-derived dendritic cells by lithium chloride," Journal of Cellular Physiology, vol. 226, no. 2, pp. 424-433, 2011.

[111] J. Komi and O. Lassila, "Nonsteroidal anti-estrogens inhibit the functional differentiation of human monocyte-derived dendritic cells," Blood, vol. 95, no. 9, pp. 2875-2882, 2000.

[112] G. M. Möller, S. E. Overbeek, C. G. Van Helden-Meeuwsen et al., "Increased numbers of dendritic cells in the bronchial mucosa of atopic asthmatic patients: downregulation by inhaled corticosteroids," Clinical and Experimental Allergy, vol. 26, no. 5, pp. 517-524, 1996. 
[113] C. Q. Xia, R. Peng, F. Beato, and M. J. Clare-Salzler, "Dexamethasone induces IL-10-producing monocyte-derived dendritic cells with durable immaturity," Scandinavian Journal of Immunology, vol. 62, no. 1, pp. 45-54, 2005.

[114] E. S. Mainali and J. G. Tew, "Dexamethasone selectively inhibits differentiation of cord blood stem cell deriveddendritic cell (DC) precursors into immature DCs," Cellular Immunology, vol. 232, no. 1-2, pp. 127-136, 2004.

[115] E. S. Mainali, T. Kikuchi, and J. G. Tew, "Dexamethasone inhibits maturation and alters function of monocyte-derived dendritic cells from cord blood," Pediatric Research, vol. 58, no. 1, pp. 125-131, 2005.

[116] G. T. Verhoeven, J. M. W. Van Haarst, H. J. De Wit, P. J. Simons, H. C. Hoogsteden, and H. A. Drexhage, "Glucocorticoids hamper the ex vivo maturation of lung dendritic cells from their low autofluorescent precursors in the human bronchoalveolar lavage: decreases in allostimulatory capacity and expression of CD80 and CD86," Clinical and Experimental Immunology, vol. 122, no. 2, pp. 232-240, 2000.

[117] A. Giuliani, S. A. Porcelli, L. Tentori et al., "Effect of rifampin on CD1b expression and double-negative $\mathrm{T}$ cell responses against mycobacteria-derived glycolipid antigen," Life Sciences, vol. 63, no. 12, pp. 985-994, 1998.

[118] L. Tentori, G. Graziani, S. A. Porcelli et al., "Rifampin increases cytokine-induced expression of the CD1b molecule in human peripheral blood monocytes," Antimicrobial Agents and Chemotherapy, vol. 42, no. 3, pp. 550-554, 1998.

[119] A. Giuliani, L. Tentori, R. Pepponi et al., "Cytokine-induced expression of CD1b molecules by peripheral blood monocytes: influence of $3^{\prime}$-azido-3' -deoxythymidine," Pharmacological Research, vol. 35, no. 2, pp. 135-140, 1997.

[120] G. F. Lu, F. A. Tang, P. Y. Zheng, P. C. Yang, and Y. M. Qi, "Entecavir up-regulates dendritic cell function in patients with chronic hepatitis B," World Journal of Gastroenterology, vol. 14, no. 10, pp. 1617-1621, 2008.

[121] Y. J. Chen, K. S. C. Chao, Y. C. Yang, M. L. Hsu, C. P. Lin, and Y. Y. Chen, "Zoledronic acid, an aminobisphosphonate, modulates differentiation and maturation of human dendritic cells," Immunopharmacology and Immunotoxicology, vol. 31, no. 3, pp. 499-508, 2009.

[122] E. den Dekker, S. Grefte, T. Huijs et al., "Monocyte cell surface glycosaminoglycans positively modulate IL-4induced differentiation toward dendritic cells," Journal of Immunology, vol. 180, no. 6, pp. 3680-3688, 2008.

[123] A. Nencioni, J. Beck, D. Werth et al., "Histone deacetylase inhibitors affect dendritic cell differentiation and immunogenicity," Clinical Cancer Research, vol. 13, no. 13, pp. 39333941, 2007.

[124] C. R. Nascimento, C. G. Freire-de-Lima, A. da Silva de Oliveira, F. D. Rumjanek, and V. M. Rumjanek, "The short chain fatty acid sodium butyrate regulates the induction of CD1a in developing dendritic cells," Immunobiology, vol. 216, no. 3, pp. 275-284, 2011.

[125] K. J. Smith, S. Hamza, and H. Skelton, "Topical imidazoquinoline therapy of cutaneous squamous cell carcinoma polarizes lymphoid and monocyte/macrophage populations to a Th1 and M1 cytokine pattern," Clinical and Experimental Dermatology, vol. 29, no. 5, pp. 505-512, 2004.

[126] Y. Q. Shu and Y. Gu, "The effect of dendritic cells activated by OK-432 and pulsed with antigens on cytokine induced killers," Biomedicine and Pharmacotherapy, vol. 60, no. 4, pp. 156-160, 2006.
[127] Z. Y. Wang, A. Morinobu, S. Kawano, J. Saegusa, B. Wang, and S. Kumagai, "Gold sodium thiomalate suppresses the differentiation and function of human dendritic cells from peripheral blood monocytes," Clinical and Experimental Rheumatology, vol. 20, no. 5, pp. 683-688, 2002.

[128] M. Ruggieri, C. Pica, A. Lia et al., "Combination treatment of glatiramer acetate and minocycline affects phenotype expression of blood monocyte-derived dendritic cells in Multiple Sclerosis patients," Journal of Neuroimmunology, vol. 197, no. 2, pp. 140-146, 2008.

[129] Y. Hussein, A. Sanna, M. Söderström, H. Link, and Y. M. Huang, "Multiple sclerosis: expression of CDIa and production of IL-12 p70 and IFN- $\gamma$ by blood mononuclear cells in patients on combination therapy with IFN- $\beta$ and glatiramer acetate compared to monotherapy with IFN- $\beta$," Multiple Sclerosis, vol. 10, no. 1, pp. 16-25, 2004.

[130] Y. Hussien, A. Sanna, M. Söderström, H. Link, and YU. M. Huang, "Glatiramer acetate and IFN- $\beta$ act on dendritic cells in multiple sclerosis," Journal of Neuroimmunology, vol. 121, no. 1-2, pp. 102-110, 2001.

[131] N. H. R. Litjens, M. Rademaker, B. Ravensbergen, H. B. Thio, J. T. Van Dissel, and P. H. Nibbering, "Effects of monomethylfumarate on dendritic cell differentiation," British Journal of Dermatology, vol. 154, no. 2, pp. 211-217, 2006.

[132] F. S. Kalthoff, J. Chung, P. Musser, and A. Stuetz, "Pimecrolimus does not affect the differentiation, maturation and function of human monocyte-derived dendritic cells, in contrast to corticosteroids," Clinical and Experimental Immunology, vol. 133, no. 3, pp. 350-359, 2003.

[133] D. Simon, E. Vassina, S. Yousefi, L. R. Braathen, and H. U. Simon, "Inflammatory cell numbers and cytokine expression in atopic dermatitis after topical pimecrolimus treatment," Allergy, vol. 60, no. 7, pp. 944-951, 2005.

[134] P. Monti, A. Mercalli, B. E. Leone, D. C. Valerio, P. Allavena, and L. Piemonti, "Rapamycin impairs antigen uptake of human dendritic cells," Transplantation, vol. 75, no. 1, pp. 137-145, 2003.

[135] Y. Chen, C. Yang, N. Jin et al., "Sinomenine promotes differentiation but impedes maturation and co-stimulatory molecule expression of human monocyte-derived dendritic cells," International Immunopharmacology, vol. 7, no. 8, pp. 1102-1110, 2007.

[136] J. Cos, T. Villalba, R. Parra et al., "FK506 in the maturation of dendritic cells," Haematologica, vol. 87, no. 7, pp. 679-687, 2002.

[137] A. Wollenberg, S. Sharma, D. von Bubnoff, E. Geiger, J. Haberstok, and T. Bieber, "Topical tacrolimus (FK506) leads to profound phenotypic and functional alterations of epidermal antigen-presenting dendritic cells in atopic dermatitis," Journal of Allergy and Clinical Immunology, vol. 107, no. 3, pp. 519-525, 2001.

[138] K. Shimizu, S. I. Fujii, K. Fujimoto, K. Kawa, A. Yamada, and F. Kawano, "Tacrolimus (FK506) treatment of CD34 hematopoietic progenitor cells promote the development of dendritic cells that drive $\mathrm{CD} 44^{+} \mathrm{T}$ cells toward Th2 responses," Journal of Leukocyte Biology, vol. 68, no. 5, pp. 633-640, 2000.

[139] K. J. Zhu, Q. Y. Shen, H. Cheng, X. H. Mao, LI. M. Lao, and G. L. Hao, "Triptolide affects the differentiation, maturation and function of human dendritic cells," International Immunopharmacology, vol. 5, no. 9, pp. 1415-1426, 2005.

[140] A. Del Prete, P. Zaccagnino, M. Di Paola et al., "Role of mitochondria and reactive oxygen species in dendritic 
cell differentiation and functions," Free Radical Biology and Medicine, vol. 44, no. 7, pp. 1443-1451, 2008.

[141] R. van de Ven, M. C. de Jong, A. W. Reurs et al., "Dendritic cells require multidrug resistance protein 1 (ABCC1) transporter activity for differentiation," Journal of Immunology, vol. 176, no. 9, pp. 5191-5198, 2006.

[142] C. Bedini, F. Nasorri, G. Girolomoni, O. De Pità, and A. Cavani, "Antitumour necrosis factor- $\alpha$ chimeric antibody (infliximab) inhibits activation of skin-homing $\mathrm{CD}^{+}$and $\mathrm{CD}^{+} \mathrm{T}$ lymphocytes and impairs dendritic cell function," British Journal of Dermatology, vol. 157, no. 2, pp. 249-258, 2007.

[143] B. Bufan, S. Mojsilović, D. Vučićević et al., "Comparative effects of aspirin and NO-releasing aspirins on differentiation, maturation and function of human monocyte-derived dendritic cells in vitro," International Immunopharmacology, vol. 9, no. 7-8, pp. 910-917, 2009.

[144] U. Švajger, A. Vidmar, and M. Jeras, "Niflumic acid renders dendritic cells tolerogenic and up-regulates inhibitory molecules ILT3 and ILT4," International Immunopharmacology, vol. 8, no. 7, pp. 997-1005, 2008.

[145] A. Kaser, D. L. Hava, S. K. Dougan et al., "Microsomal triglyceride transfer protein regulates endogenous and exogenous antigen presentation by group 1 CD1 molecules," European Journal of Immunology, vol. 38, no. 8, pp. 2351-2359, 2008.

[146] V. Fernández-Ruiz, A. González, and N. López-Moratalla, "Effect of nitric oxide in the differentiation of human monocytes to dendritic cells," Immunology Letters, vol. 93, no. 1, pp. 87-95, 2004.

[147] P. López, C. Gutiérrez, A. Suárez et al., "IFN $\alpha$ treatment generates antigen-presenting cells insensitive to atorvastatin inhibition of MHC-II expression," Clinical Immunology, vol. 129, no. 2, pp. 350-359, 2008.

[148] H. Bartosik-Psujek, J. Tabarkiewicz, K. Pocinska, S. Radej, Z. Stelmasiak, and J. Rolinski, "Immunomodulatory effects of IFN- $\beta$ and lovastatin on immunophenotype of monocytederived dendritic cells in multiple sclerosis," Archivum Immunologiae et Therapiae Experimentalis, vol. 58, no. 4, pp. 313-319, 2010.

[149] M. Sioud and Y. Fløisand, "TLR agonists induce the differentiation of human bone marrow $\mathrm{CD} 34^{+}$progenitors into CD11c ${ }^{+} \mathrm{CD} 80 / 86^{+}$DC capable of inducing a Th1-type response," European Journal of Immunology, vol. 37, no. 10, pp. 2834-2846, 2007.

[150] S. Appel, A. Rupf, M. M. Weck et al., "Effects of imatinib on monocyte-derived dendritic cells are mediated by inhibition of nuclear factor- $\kappa \mathrm{B}$ and Akt signaling pathways," Clinical Cancer Research, vol. 11, no. 5, pp. 1928-1940, 2005.

[151] S. Appel, A. M. Boehmler, F. Grünebach et al., "Imatinib mesylate affects the development and function of dendritic cells generated from $\mathrm{CD} 34^{+}$peripheral blood progenitor cells," Blood, vol. 103, no. 2, pp. 538-544, 2004.

[152] M. M. Hipp, N. Hilf, S. Walter et al., "Sorafenib, but not sunitinib, affects function of dendritic cells and induction of primary immune responses," Blood, vol. 111, no. 12, pp. 5610-5620, 2008.

[153] M. Mohty, S. Morbelli, D. Isnardon et al., "All-trans retinoic acid skews monocyte differentiation into interleukin-12secreting dendritic-like cells," British Journal of Haematology, vol. 122, no. 5, pp. 829-836, 2003.

[154] Y. Wada, T. Hisamatsu, N. Kamada, S. Okamoto, and T. Hibi, "Retinoic acid contributes to the induction of IL-12hypoproducing dendritic cells," Inflammatory Bowel Diseases, vol. 15, no. 10, pp. 1548-1556, 2009.
[155] P. Schütt, U. Buttkereit, D. Brandhorst et al., "In vitro dendritic cell generation and lymphocyte subsets in myeloma patients: influence of thalidomide and high-dose chemotherapy treatment," Cancer Immunology, Immunotherapy, vol. 54, no. 5, pp. 506-512, 2005.

[156] S. J. Oliver, T. Kikuchi, J. G. Krueger, and G. Kaplan, "Thalidomide induces granuloma differentiation in sarcoid skin lesions associated with disease improvement," Clinical Immunology, vol. 102, no. 3, pp. 225-236, 2002.

[157] T. R. Coven, F. P. Murphy, P. Gilleaudeau, I. Cardinale, and J. G. Krueger, "Trimethylpsoralen bath PUVA is a remittive treatment for psoriasis vulgaris: evidence that epidermal immunocytes are direct therapeutic targets," Archives of Dermatology, vol. 134, no. 10, pp. 1263-1268, 1998.

[158] M. O. Canning, K. Grotenhuis, H. J. de Wit, and H. A. Drexhage, "Opposing effects of dehydroepiandrosterone and dexamethasone on the generation of monocyte-derived dendritic cells," European Journal of Endocrinology, vol. 143, no. 5, pp. 687-695, 2000.

[159] M. Takei, A. Umeyama, and S. Arihara, "T-cadinol and calamenene induce dendritic cells from human monocytes and drive Th1 polarization," European Journal of Pharmacology, vol. 537, no. 1-3, pp. 190-199, 2006.

[160] M. Takei, A. Umeyama, and S. Arihara, "Epicubenol and Ferruginol induce DC from human monocytes and differentiate IL-10-producing regulatory T cells in vitro," Biochemical and Biophysical Research Communications, vol. 337, no. 2, pp. 730-738, 2005.

[161] M. Takei, A. Umeyama, S. Arihara, and H. Matsumoto, "Effect of piceatannol in human monocyte-derived dendritic cells in vitro," Journal of Pharmaceutical Sciences, vol. 94, no. 5, pp. 974-982, 2005.

[162] M. Takei, E. Tachikawa, H. Hasegawa, and J.-J. Lee, "Dendritic cells maturation promoted by $\mathrm{M} 1$ and $\mathrm{M} 4$, end products of steroidal ginseng saponins metabolized in digestive tracts, drive a potent Th1 polarization," Biochemical Pharmacology, vol. 68, no. 3, pp. 441-452, 2004.

[163] M. O. Canning, K. Grotenhuis, H. de Wit, C. Ruwholf, and H. A. Drexhage, "1- $\alpha, 25$-dihydroxyvitamin $\mathrm{D}_{3}\left(1,25(\mathrm{OH})_{2} \mathrm{D}_{3}\right)$ hampers the maturation of fully active immature dendritic cells from monocytes," European Journal of Endocrinology, vol. 145, no. 3, pp. 351-357, 2001.

[164] A. Berer, J. Stöckl, O. Majdic et al., "1,25-Dihydroxyvitamin $\mathrm{D}_{3}$ inhibits dendritic cell differentiation and maturation in vitro," Experimental Hematology, vol. 28, no. 5, pp. 575-583, 2000.

[165] H. Bartosik-Psujek, J. Tabarkiewicz, K. Pocinska, Z. Stelmasiak, and J. Rolinski, "Immunomodulatory effects of vitamin $\mathrm{D}_{3}$ on monocyte-derived dendritic cells in multiple sclerosis," Multiple Sclerosis, vol. 16, no. 12, pp. 1513-1516, 2010.

[166] A. W. Pedersen, K. Holmstrøm, S. S. Jensen et al., "Phenotypic and functional markers for $1 \alpha, 25$-dihydroxyvitamin $\mathrm{D}_{3}$-modified regulatory dendritic cells," Clinical and Experimental Immunology, vol. 157, no. 1, pp. 48-59, 2009.

[167] K. Zhu, R. Gläser, and U. Mrowietz, "Vitamin $D_{3}$ and analogues modulate the expression of CSF-1 and its receptor in human dendritic cells," Biochemical and Biophysical Research Communications, vol. 297, no. 5, pp. 1211-1217, 2002.

[168] L. Piemonti, P. Monti, M. Sironi et al., "Vitamin $D_{3}$ affects differentiation, maturation, and function of human monocyte-derived dendritic cells," Journal of Immunology, vol. 164, no. 9, pp. 4443-4451, 2000. 
[169] J. Reichrath, S. M. Müller, A. Kerber, H. P. Baum, and F. A. Bahmer, "Biologic effects of topical calcipotriol $\left(\mathrm{MC}_{903}\right)$ treatment in psoriatic skin," Journal of the American Academy of Dermatology, vol. 36, no. 1, pp. 19-28, 1997.

[170] M. Herfs, L. Herman, P. Hubert et al., "High expression of $\mathrm{PGE}_{2}$ enzymatic pathways in cervical (pre)neoplastic lesions and functional consequences for antigen-presenting cells," Cancer Immunology, Immunotherapy, vol. 58, no. 4, pp. 603614, 2009.

[171] J. J. Lee, M. Takei, S. Hori et al., "The role of $\mathrm{PGE}^{2}$ in the differentiation of dendritic cells: how do dendritic cells influence T-cell polarization and chemokine receptor expression?" Stem Cells, vol. 20, no. 5, pp. 448-459, 2002.

[172] P. Kaliński, C. M. U. Hilkens, A. Snijders, F. G. M. Snijdewint, and M. L. Kapsenberg, "IL-12-deficient dendritic cells, generated in the presence of prostaglandin E, promote type 2 cytokine production in maturing human naive $\mathrm{T}$ helper cells," Journal of Immunology, vol. 159, no. 1, pp. 28-35, 1997.

[173] P. Kaliński, C. M. U. Hilkens, A. Snijders, F. G. M. Snijdewint, and M. L. Kapsenberg, "Dendritic cells, obtained from peripheral blood precursors in the presence of PGE2, promote Th2 responses," Advances in Experimental Medicine and Biology, vol. 417, pp. 363-367, 1997.

[174] C. C. Sombroek, A. G. M. Stam, A. J. Masterson et al., "Prostanoids play a major role in the primary tumorinduced inhibition of dendritic cell differentiation," Journal of Immunology, vol. 168, no. 9, pp. 4333-4343, 2002.

[175] A. Nencioni, K. Lauber, F. Grünebach et al., "Cyclopentenone prostaglandins induce caspase activation and apoptosis in dendritic cells by a PPAR- $\gamma$-independent mechanism: regulation by inflammatory and T cell-derived stimuli," Experimental Hematology, vol. 30, no. 9, pp. 1020-1028, 2002.

[176] N. Katoh, F. Soga, T. Nara et al., "Effect of serotonin on the differentiation of human monocytes into dendritic cells," Clinical and Experimental Immunology, vol. 146, no. 2, pp. 354-361, 2006.

[177] L. G. Radvanyi, A. Banerjee, M. Weir, and H. Messner, "Low levels of interferon- $\alpha$ induce CD86 (B7.2) expression and accelerates dendritic cell maturation from human peripheral blood mononuclear cells," Scandinavian Journal of Immunology, vol. 50, no. 5, pp. 499-509, 1999.

[178] S. L. Pogue, B. T. Preston, J. Stalder, C. R. Bebbington, and P. M. Cardarelli, "The receptor for type I IFNs is highly expressed on peripheral blood B cells and monocytes and mediates a distinct profile of differentiation and activation of these cells," Journal of Interferon and Cytokine Research, vol. 24, no. 2, pp. 131-139, 2004.

[179] M. Merad, E. Angevin, J. Wolfers et al., "Generation of monocyte-derived dendritic cells from patients with renal cell cancer: modulation of their functional properties after therapy with biological response modifiers (IFN- $\alpha$ plus IL2 and IL-12)," Journal of Immunotherapy, vol. 23, no. 3, pp. 369-378, 2000.

[180] Y. M. Huang, S. Adikari, U. Båve, A. Sanna, and G. Alm, "Multiple sclerosis: Interferon-beta induces CD $123^{+} \mathrm{BDCA}^{-}$dendritic cells that produce IL- 6 and IL-10 and have no enhanced type I interferon production," Journal of Neuroimmunology, vol. 158, no. 1-2, pp. 204-212, 2005.

[181] Y. C. Q. Zang, S. M. Skinner, R. R. Robinson et al., "Regulation of differentiation and functional properties of monocytes and monocyte-derived dendritic cells by interferon beta in multiple sclerosis," Multiple Sclerosis, vol. 10, no. 5, pp. 499-506, 2004.
[182] E. J. Bartholomé, F. Willems, A. Crusiaux, K. Thielemans, L. Schandene, and M. Goldman, "IFN- $\beta$ interferes with the differentiation of dendritic cells from peripheral blood mononuclear cells: selective inhibition of CD40-dependent interleukin-12 secretion," Journal of Interferon and Cytokine Research, vol. 19, no. 5, pp. 471-478, 1999.

[183] Y. Hussein, A. Sanna, M. Söderström, H. Link, and Y. M. Huang, "Multiple sclerosis: expression of CDIa and production of IL-12 p70 and IFN- $\gamma$ by blood mononuclear cells in patients on combination therapy with IFN- $\beta$ and glatiramer acetate compared to monotherapy with IFN- $\beta$," Multiple Sclerosis, vol. 10, no. 1, pp. 16-25, 2004.

[184] B. L. McRae, T. Nagai, R. T. Semnani, J. M. Van Seventer, and G. A. Van Seventer, "Interferon- $\alpha$ and $-\beta$ inhibit the in vitro differentiation of immunocompetent human dendritic cells from CD14 precursors," Blood, vol. 96, no. 1, pp. 210-217, 2000.

[185] Y. Hussien, A. Sanna, M. Söderström, H. Link, and Y. M. Huang, "Glatiramer acetate and IFN- $\beta$ act on dendritic cells in multiple sclerosis," Journal of Neuroimmunology, vol. 121, no. 1-2, pp. 102-110, 2001.

[186] Y. Rongcun, H. Maes, M. Corsi, F. Dellner, T. Wen, and R. Kiessling, "Interferon $\gamma$ impairs the ability of monocytederived dendritic cells to present tumour-specific and allospecific antigens and reduces their expression of CD1a, CD80 and CD4," Cytokine, vol. 10, no. 10, pp. 747-755, 1998.

[187] Y. Delneste, P. Charbonnier, N. Herbault et al., "Interferonswitches monocyte differentiation from dendritic cells to macrophages," Blood, vol. 101, no. 1, pp. 143-150, 2003.

[188] M. Makino, Y. Maeda, T. Mukai, and S. H. E. Kaufmann, "Impaired maturation and function of dendritic cells by mycobacteria through IL-1 $\beta$," European Journal of Immunology, vol. 36, no. 6, pp. 1443-1452, 2006.

[189] N. Gupta, A. P. Barhanpurkar, G. B. Tomar et al., "IL3 inhibits human osteoclastogenesis and bone resorption through downregulation of c-Fms and diverts the cells to dendritic cell lineage," Journal of Immunology, vol. 185, no. 4, pp. 2261-2272, 2010.

[190] K. Yamamura, K. Ohishi, N. Katayama et al., "Notch ligand Delta-1 differentially modulates the effects of gp130 activation on interleukin- 6 receptor $\alpha$-positive and -negative human hematopoietic progenitors," Cancer Science, vol. 98, no. 10, pp. 1597-1603, 2007.

[191] A. Encabo, P. Solves, E. Mateu, P. Sepúlveda, F. CarbonellUberos, and M. D. Miñana, "Selective generation of different dendritic cell precursors from $\mathrm{CD} 34^{+}$cells by interleukin-6 and interleukin-3," Stem Cells, vol. 22, no. 5, pp. 725-740, 2004.

[192] Z. Yu, W. Liu, D. Liu, and LI. Fan, "The regulatory role of Hyper-IL-6 in the differentiation of myeloid and erythroid progenitors derived from human cord blood," Cellular Immunology, vol. 241, no. 1, pp. 32-37, 2006.

[193] M. Ratta, F. Fagnoni, A. Curti et al., "Dendritic cells are functionally defective in multiple myeloma: the role of interleukin-6," Blood, vol. 100, no. 1, pp. 230-237, 2002.

[194] P. Chomarat, J. Banchereau, J. Davoust, and A. K. Palucka, "IL-6 switches the differentiation of monocytes from dendritic cells to macrophages," Nature Immunology, vol. 1, no. 6, pp. 510-514, 2000.

[195] K. Asadullah, M. Friedrich, S. Hanneken et al., "Effects of systemic interleukin-10 therapy on psoriatic skin lesions: histologic, immunohistologic, and molecular biology findings," Journal of Investigative Dermatology, vol. 116, no. 5, pp. 721727, 2001. 
[196] D. Longoni, L. Piemonti, S. Bernasconi, A. Mantovani, and P. Allavena, "Interleukin-10 increases mannose receptor expression and endocytic activity in monocyte-derived dendritic cells," International Journal of Clinical and Laboratory Research, vol. 28, no. 3, pp. 162-169, 1998.

[197] P. Allavena, L. Piemonti, D. Longoni et al., "IL-10 prevents the differentiation of monocytes to dendritic cells but promotes their maturation to macrophages," European Journal of Immunology, vol. 28, no. 1, pp. 359-369, 1998.

[198] K. Sato, H. Nagayama, K. Tadokoro, T. Juji, and T. A. Takahashi, "Interleukin-13 is involved in functional maturation of human peripheral blood monocyte-derived dendritic cells," Experimental Hematology, vol. 27, no. 2, pp. 326-336, 1999.

[199] C. Q. Xia and K. J. Kao, "Effect of CXC chemokine platelet factor 4 on differentiation and function of monocyte-derived dendritic cells," International Immunology, vol. 15, no. 8, pp. 1007-1015, 2003.

[200] E. Riedl, J. Stöckl, O. Majdic, C. Scheinecker, W. Knapp, and H. Strobl, "Ligation of E-cadherin on in vitro-generated immature Langerhans-type dendritic cells inhibits their maturation," Blood, vol. 96, no. 13, pp. 4276-4284, 2000.

[201] Y. L. Lin, Y. C. Liang, and B. L. Chiang, "Placental growth factor down-regulates type $1 \mathrm{~T}$ helper immune response by modulating the function of dendritic cells," Journal of Leukocyte Biology, vol. 82, no. 6, pp. 1473-1480, 2007.

[202] C. L. Miller-Graziano, A. De, K. Laudanski, T. Herrmann, and S. Bandyopadhyay, "HSP27: an anti-inflammatory and immunomodulatory stress protein acting to dampen immune function," Novartis Foundation Symposium, vol. 291, pp. 196-208, 2008.

[203] K. Laudanski, A. De, and C. Miller-Graziano, "Exogenous heat shock protein 27 uniquely blocks differentiation of monocytes to dendritic cells," European Journal of Immunology, vol. 37, no. 10, pp. 2812-2824, 2007.

[204] E. A. Laborde, S. Vanzulli, M. Beigier-Bompadre et al., "Immune complexes inhibit differentiation, maturation, and function of human monocyte-derived dendritic cells," Journal of Immunology, vol. 179, no. 1, pp. 673-681, 2007.

[205] L. P. Rennalls, T. Seidl, J. M. G. Larkin et al., "The melanocortin receptor agonist NDP-MSH impairs the allostimulatory function of dendritic cells," Immunology, vol. 129, no. 4, pp. 610-619, 2010.

[206] S. Buisson and F. Triebel, "LAG-3 (CD223) reduces macrophage and dendritic cell differentiation from monocyte precursors," Immunology, vol. 114, no. 3, pp. 369-374, 2005.

[207] P. Gogolak, B. Rethi, I. Szatmari et al., "Differentiation of $\mathrm{CDla}^{+}$and $\mathrm{CDla}^{-}$monocyte-derived dendritic cells is biased by lipid environment and PPAR $\gamma$," Blood, vol. 109, no. 2, pp. 643-652, 2007.

[208] A. Martino, E. Volpe, and P. M. Baldini, "The influence of lysophosphatidic acid on the immunophenotypic differentiation of human monocytes into dendritic cells," Haematologica, vol. 91, no. 9, pp. 1273-1274, 2006.

[209] S. Blüml, G. Zupkovitz, S. Kirchberger et al., "Epigenetic regulation of dendritic cell differentiation and function by oxidized phospholipids," Blood, vol. 114, no. 27, pp. 54815489, 2009.

[210] L. Li, S. P. Li, J. Min, and L. Zheng, "Hepatoma cells inhibit the differentiation and maturation of dendritic cells and increase the production of regulatory T cells," Immunology Letters, vol. 114, no. 1, pp. 38-45, 2007.

[211] C. Menetrier-Caux, G. Montmain, M. C. Dieu et al., "Inhibition of the differentiation of dendritic cells from
$\mathrm{CD} 34^{+}$progenitors by tumor cells: role of interleukin- 6 and macrophage colony- stimulating factor," Blood, vol. 92, no. 12, pp. 4778-4791, 1998.

[212] J. M. Motta, C. R. Nascimento, and V. M. Rumjanek, "Leukemic cell products down-regulate human dendritic cell differentiation," Cancer Immunology, Immunotherapy, vol. 59, no. 11, pp. 1645-1653, 2010.

[213] G. Gerlini, A. Tun-Kyi, C. Dudli, G. Burg, N. Pimpinelli, and F. O. Nestle, "Metastatic melanoma secreted IL-10 downregulates CD1 molecules on dendritic cells in metastatic tumor lesions," American Journal of Pathology, vol. 165, no. 6, pp. 1853-1863, 2004.

[214] O. Berthier-Vergnes, M. Gaucherand, J. Péguet-Navarro et al., "Human melanoma cells inhibit the earliest differentiation steps of human Langerhans cell precursors but failed to affect the functional maturation of epidermal Langerhans cells," British Journal of Cancer, vol. 85, no. 12, pp. 19441951, 2001.

[215] C. C. Sombroek, A. G. M. Stam, A. J. Masterson et al., "Prostanoids play a major role in the primary tumorinduced inhibition of dendritic cell differentiation," Journal of Immunology, vol. 168, no. 9, pp. 4333-4343, 2002.

[216] D. Giordano, D. M. Magaletti, E. A. Clark, and J. A. Beavo, "Cyclic nucleotides promote monocyte differentiation toward a DC-SIGN ${ }^{+}$(CD209) intermediate cell and impair differentiation into dendritic cells," Journal of Immunology, vol. 171, no. 12, pp. 6421-6430, 2003.

[217] D. S. Leslie, C. C. Dascher, K. Cembrola et al., "Serum lipids regulate dendritic cell CD1 expression and function," Immunology, vol. 125, no. 3, pp. 289-301, 2008.

[218] M. A. Jakobsen, B. K. Møller, and S. T. Lillevang, "Serum concentration of the growth medium markedly affects monocyte-derived dendritic cells' phenotype, cytokine production profile and capacities to stimulate in MLR," Scandinavian Journal of Immunology, vol. 60, no. 6, pp. 584-591, 2004.

[219] M. Loudovaris, M. Hansen, Y. Suen, S. M. Lee, P. Casing, and J. G. Bender, "Differential effects of autologous serum on $\mathrm{CD}_{3} 4^{+}$or monocyte-derived dendritic cells," Journal of Hematotherapy and Stem Cell Research, vol. 10, no. 4, pp. 569-578, 2001.

[220] A. Smed-Sörensen, M. Moll, T. Y. Cheng et al., "IgG regulates the CD1 expression profile and lipid antigen-presenting function in human dendritic cells via Rr $\gamma$ RIIa," Blood, vol. 111, no. 10, pp. 5037-5046, 2008.

[221] K. Ohkuma, T. Sasaki, S. Kamei et al., "Modulation of dendritic cell development by immunoglobulin $\mathrm{G}$ in control subjects and multiple sclerosis patients," Clinical and Experimental Immunology, vol. 150, no. 3, pp. 397-406, 2007.

[222] J. Xie, Y. Wang, M. E. Freeman III, B. Barlogie, and Q. Yi, “ $\beta$ microglobulin as a negative regulator of the immune system: high concentrations of the protein inhibit in vitro generation of functional dendritic cells," Blood, vol. 101, no. 10, pp. 4005-4012, 2003.

[223] O. Dumay, A. Karam, L. Vian et al., "Ultraviolet AI exposure of human skin results in Langerhans cell depletion and reduction of epidermal antigen-presenting cell function: partial protection by a broad-spectrum sunscreen," British Journal of Dermatology, vol. 144, no. 6, pp. 1161-1168, 2001.

[224] M. Hochberg and C. D. Enk, "Partial protection against epidermal IL-10 transcription and langerhans cell depletion by sunscreens after exposure of human skin to UVB," Photochemistry and Photobiology, vol. 70, no. 5, pp. 766-772, 1999. 
[225] K. Kang, A. C. Gilliam, G. Chen, E. Tootell, and K. D. Cooper, "In human skin, UVB initiates early induction of IL-10 over IL-12 preferentially in the expanding dermal monocytic/macrophagic population," Journal of Investigative Dermatology, vol. 111, no. 1, pp. 31-38, 1998.

[226] V. M. Borderie, B. M. Kantelip, P. O. Genin, M. Masse, L. Laroche, and B. Y. Delbosc, "Modulation of HLA-DR and CD1a expression on human cornea with low-dose UVB irradiation," Current Eye Research, vol. 15, no. 6, pp. 669-679, 1996.

[227] P. Mitchell, C. Germain, P. L. Fiori et al., "Chronic exposure to Helicobacter pylori impairs dendritic cell function and inhibits Th1 development," Infection and Immunity, vol. 75, no. 2, pp. 810-819, 2007.

[228] S. Krauss-Etschmann, R. Gruber, K. Plikat et al., "Increase of antigen-presenting cells in the gastric mucosa of Helicobacter pylori-infected children," Helicobacter, vol. 10, no. 3, pp. 214 222, 2005.

[229] A. Michalak-Stoma, J. Tabarkiewicz, A. Olender et al., "The effect of Propionibacterium acnes on maturation of dendritic cells derived from acne patients' peripherial blood mononuclear cells," Folia Histochemica et Cytobiologica, vol. 46, no. 4, pp. 535-539, 2008.

[230] J. Correale and M. Farez, "Monocyte-derived dendritic cells in multiple sclerosis: the effect of bacterial infection," Journal of Neuroimmunology, vol. 190, no. 1-2, pp. 177-189, 2007.

[231] T. Agrawal, V. Vats, P. K. Wallace, S. Salhan, and A. Mittal, "Role of cervical dendritic cell subsets, co-stimulatory molecules, cytokine secretion profile and beta-estradiol in development of sequalae to Chlamydia trachomatis infection," Reproductive Biology and Endocrinology, vol. 6, article no. 46, 2008.

[232] X. Chen and L. J. Chang, "Mycoplasma-mediated alterations of in vitro generation and functions of human dendritic cells," Journal of Biomedical Science, vol. 12, no. 1, pp. 31-46, 2005.

[233] J. L. Amprey, G. F. Späth, and S. A. Porcelli, "Inhibition of CD1 expression in human dendritic cells during intracellular infection with Leishmania donovani," Infection and Immunity, vol. 72, no. 1, pp. 589-592, 2004.

[234] C. Favali, N. Tavares, J. Clarêncio, A. Barral, M. BarralNetto, and C. Brodskyn, "Leishmania amazonensis infection impairs differentiation and function of human dendritic cells," Journal of Leukocyte Biology, vol. 82, no. 6, pp. 14011406, 2007.

[235] M. J. Donovan, A. Jayakumar, and M. A. McDowell, "Inhibition of groups 1 and 2 CD1 molecules on human dendritic cells by Leishmania species," Parasite Immunology, vol. 29, no. 10, pp. 515-524, 2007.

[236] D. Seipel, F. L. Ribeiro-Gomes, M. W. Barcelos et al., "Monocytes/macrophages infected with Toxoplasma gondii do not increase co-stimulatory molecules while maintaining their migratory ability," APMIS, vol. 117, no. 9, pp. 672-680, 2009.

[237] R. T. Fujiwara, G. G. L. Cançado, P. A. Freitas et al., "Necator americanus infection: a possible cause of altered dendritic cell differentiation and eosinophil profile in chronically infected individuals," PLoS Neglected Tropical Diseases, vol. 3, no. 3, article e399, 2009.

[238] R. Riganò, B. Buttari, E. Profumo et al., "Echinococcus granulosus antigen B impairs human dendritic cell differentiation and polarizes immature dendritic cell maturation towards a Th2 cell response," Infection and Immunity, vol. 75, no. 4, pp. 1667-1678, 2007.
[239] J. H. C. Kanan and B. M. Chain, "Modulation of dendritic cell differentiation and cytokine secretion by the hydatid cyst fluid of Echinococcus granulosus," Immunology, vol. 118, no. 2, pp. 271-278, 2006.

[240] M. Cirone, G. Lucania, P. Bergamo, P. Trivedi, L. Frati, and A. Faggioni, "Human herpesvirus 8 (HHV-8) inhibits monocyte differentiation into dendritic cells and impairs their immunostimulatory activity," Immunology Letters, vol. 113, no. 1, pp. 40-46, 2007.

[241] S. Gredmark and C. Söderberg-Nauclér, "Human cytomegalovirus inhibits differentiation of monocytes into dendritic cells with the consequence of depressed immunological functions," Journal of Virology, vol. 77, no. 20, pp. 10943-10956, 2003.

[242] A. Martino, E. Volpe, G. Auricchio, V. Colizzi, and P. M. Baldini, "Influence of Pertussis toxin on CDla isoform expression in human dendritic cells," Journal of Clinical Immunology, vol. 26, no. 2, pp. 153-159, 2006.

[243] M. Wang, P. K. Mukherjee, J. Chandra, A. A. Lattif, T. S. McCormick, and M. A. Ghannoum, "Characterization and partial purification of Candida albicans secretory IL-12 inhibitory factor," BMC Microbiology, vol. 8, article 31, 2008.

[244] V. Sanchez, C. Hessler, A. Demonfort, J. Lang, and B. Guy, "Comparison by flow cytometry of immune changes induced in human monocyte-derived dendritic cells upon infection with dengue 2 live-attenuated vaccine or 16681 parental strain," FEMS Immunology and Medical Microbiology, vol. 46, no. 1, pp. 113-123, 2006.

[245] O. A. Skorokhod, M. Alessio, B. Mordmüller, P. Arese, and E. Schwarzer, "Hemozoin (malarial pigment) inhibits differentiation and maturation of human monocyte-derived dendritic cells: a peroxisome proliferator-activated receptor$\gamma$-mediated effect," Journal of Immunology, vol. 173, no. 6, pp. 4066-4074, 2004.

[246] L. L. Bueno, C. G. Morais, I. S. Soares et al., "Plasmodium vivax recombinant vaccine candidate AMA-1 plays an important role in adaptive immune response eliciting differentiation of dendritic cells," Vaccine, vol. 27, no. 41, pp. 5581-5588, 2009.

[247] N. Hymery, K. Léon, F. G. Carpentier, J. L. Jung, and D. Parent-Massin, "T-2 toxin inhibits the differentiation of human monocytes into dendritic cells and macrophages," Toxicology in Vitro, vol. 23, no. 3, pp. 509-519, 2009.

[248] H. K. Kyu, H. H. Ji, H. C. Jin, H. C. Kwang, and C. E. Hee, "Role of staphylococcal superantigen in atopic dermatitis: influence on keratinocytes," Journal of Korean Medical Science, vol. 21, no. 2, pp. 315-323, 2006.

[249] J. Xie, J. Qian, S. Wang, M. E. Freeman, J. Epstein, and Q. Yi, "Novel and detrimental effects of lipopolysaccharide on in vitro generation of immature dendritic cells: involvement of mitogen-activated protein kinase p38," Journal of Immunology, vol. 171, no. 9, pp. 4792-4800, 2003. 


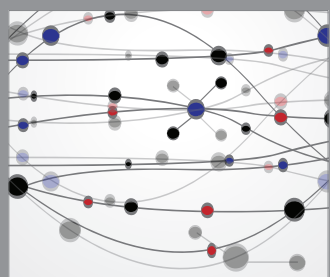

The Scientific World Journal
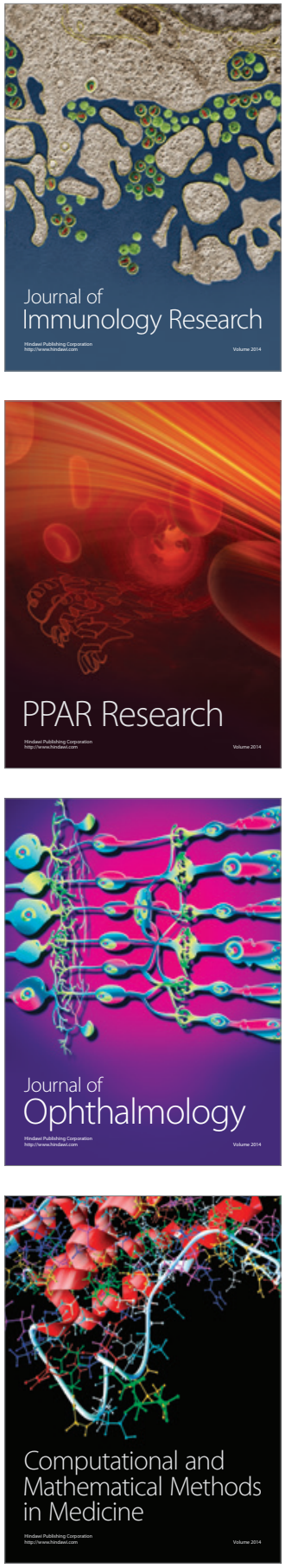

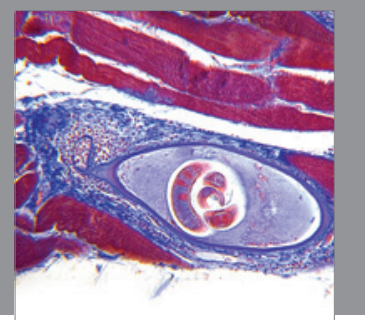

Gastroenterology

Research and Practice
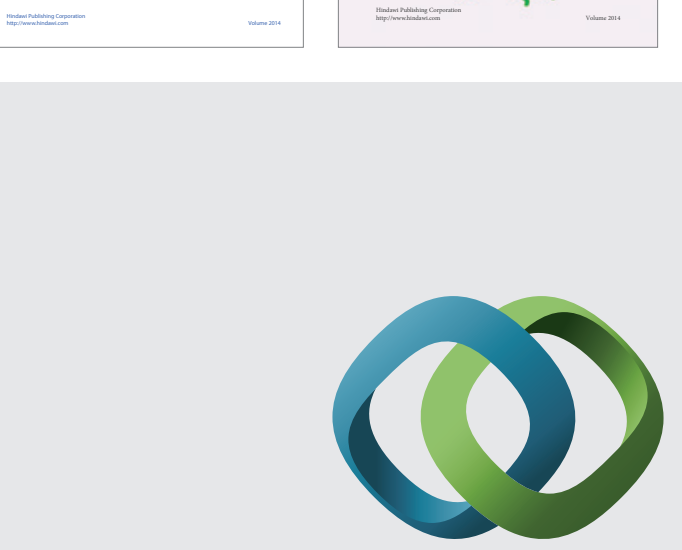

\section{Hindawi}

Submit your manuscripts at

http://www.hindawi.com
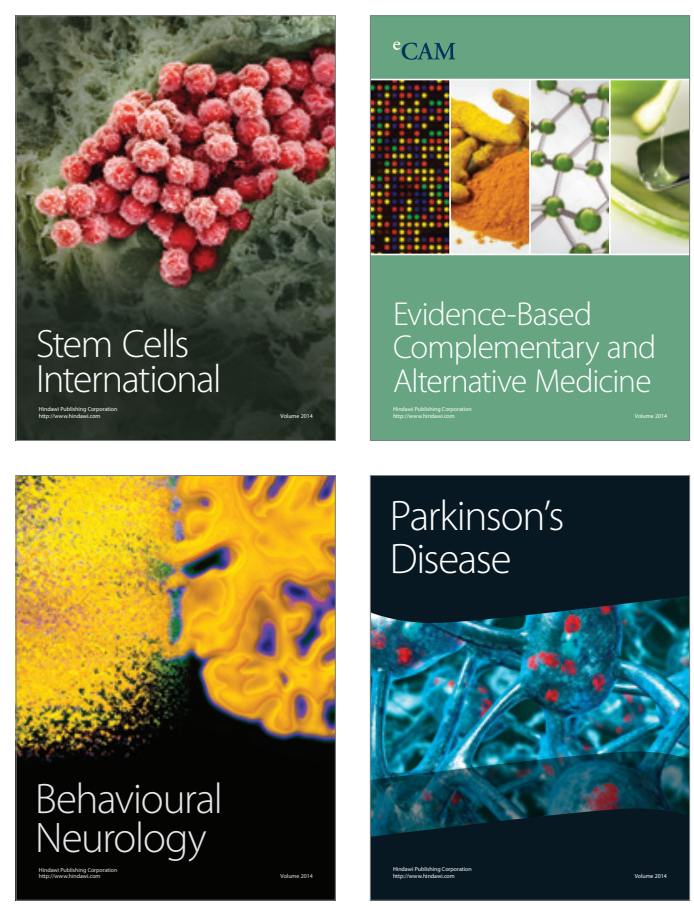

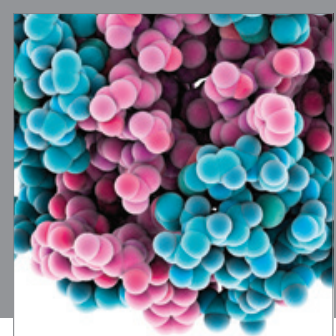

Journal of
Diabetes Research

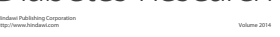

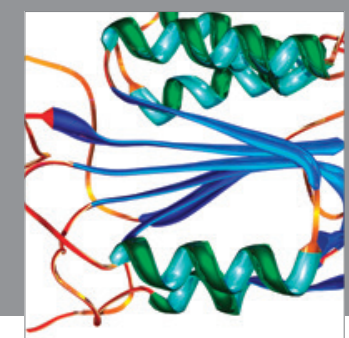

Disease Markers
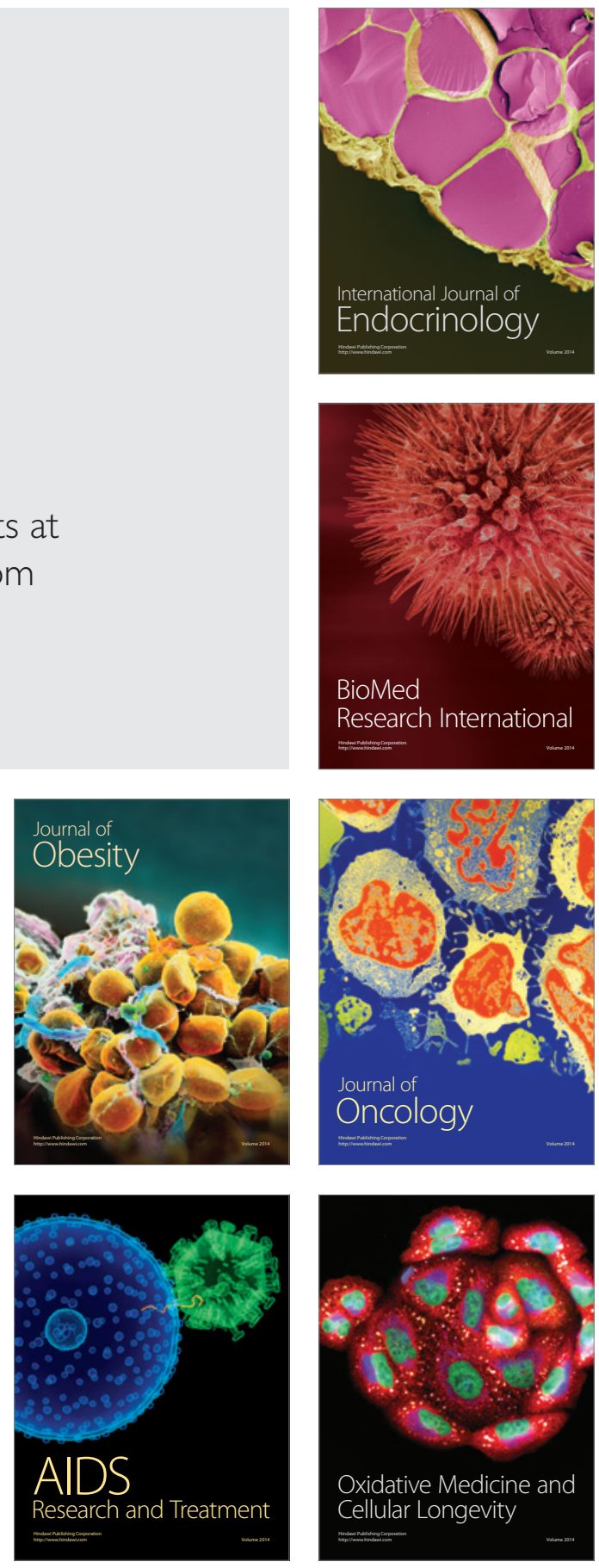